\title{
REVIEW OF SUBTRIBE APODACRINA (DIPTERA, SARCOPHAGIDAE) OF MIDDLE EAST WITH DESCRIPTIONS OF TEN NEW SPECIES
}

\author{
Yu. G. Verves ${ }^{1 *}$ L. A. Khrokalo ${ }^{2}$ \\ ${ }^{1}$ Institute for Evolutionary Ecology NAS of Ukraine, \\ Academician Lebedev st., 37, Kyiv, Ukraine 03143,E-mail yuryverves@gmail.com \\ ${ }^{2}$ National Technical University of Ukraine \\ "Igor Sikorsky Kyiv Polytechnic Institute", \\ Prospect Peremohy, 37, Kyiv, Ukraine 03056 \\ ${ }^{*}$ Corresponding author \\ Yu. G. Verves (https://orcid.org/0000-0003-4363-3062) \\ L. A. Khrokalo (https://orcid.org/0000-0003-4334-6629)
}

\begin{abstract}
Review of Subtribe Apodacrina (Diptera, Sarcophagidae) of Middle East, with Descriptions of Ten New Species. Verves, Yu. G. \& Khrokalo, L. A. - New distributional data and an updated and annotated checklist are provided for 27 species of Middle East Sarcophagidae of subtribe Apodacrina Rohdendorf. Of these, 17 species are recorded for Israel, 10 for Egypt, 4 for Turkey, 3 for Iran, 2 for each of Cyprus, Jordan, Saudi Arabia and United Arab Emirates, and 1 for Oman. No data are available for Bahrain, Iraq, Kuwait, Lebanon, Qatar, Syria and Yemen. Ten new species are described, including 5 from Israel (Apodacra idiopatica sp. n., A. melanura sp. n., Xeromyia moderabilis sp. n., X. nahalica sp. n., Xerophilomyia nigritarsus sp. n.), 2 from Saudi Arabia (Xeromyia jeddaense sp. n., X. ponti sp. n.), 1 from Cyprus (Xerophilomyia famagustica sp. n.), 1 from Egypt (Apodacra firanensis sp. n.), and 1 from Oman (Xeromyia omanica sp. n.). Comprehensive regional keys for the identification of genera and regional species are presented.

Key words: Apodacrina; Middle East; distribution; new species; keys; fauna.
\end{abstract}

\section{Introduction}

The subtribe Apodacrina Rohdendorf, 1967 has been reviewed in detail recently (Verves et al., 2015). It includes 3 genera and 54 species distributed in arid zones of the Palaearctic (southern part), Oriental and Afrotropical regions. Of these, 27 species are reported from the Middle East (table 1). We provide here an annotated checklist of Apodacrina for all countries of the Middle East. The ecological features of most species have yet to be investigated, but adults are often seen visiting flowers, and larvae are kleptoparasites in nests of solitary wasps and bees (Gorobchishin, 2006; Pape \& Blasco-Zumeta, 1997; Verves et al., 2015). 


\section{Material and methods}

This review is based on the study of specimens in the Natural History Museum, London, United Kingdom, Tel Aviv University, Israel, and the private collection of both authors. Taxonomic concepts follow our previous works (Verves, 1986; Verves \& Khrokalo, 2006; Verves et al., 2015). All photos have been prepared by Prof. K. Szpila. Terminology of morphological features follows Merz \& Haenni (2000). The specimens examined in this study are deposited in the following collections: NHMUK - Natural History Museum, London, United Kingdom; PCV - private collection of Yu. Verves and L. Khrokalo, Kyiv, Ukraine; TAU — The Steinhardt Museum of Natural History, Tel Aviv University, Israel.

The abbreviations used in the text are: $a$ - anterior setae; $a c r$ - acrostichal setae; $a d$ - anterodorsal setae; ap - apical setae; $d$ - dorsal setae; $d c$ - dorsocentral setae; $d m$ - discal medial cell; $d m$-cu - discal medialcubital crossvein; $d s-$ discal setae; $f_{1}$ - fore femur; $f_{2}-$ mid femur; $f_{3}$ - hind femur; fr - frontal setae; ia intra-alar setae; kepst - katepisternal setae; marg - marginal setae; M - medial vein; $n p l$ - notopleural setae; $o c$ - ocellar setae; orb - orbital setae; porb - postorbital setae; pprn - postpronotal setae; $r_{1}$ - marginal cell; $r_{2+3}$ - first submarginal cell; $r_{4+5}$ - second submarginal cell; $R_{4+5}$ third longitudinal vein; $r-m$ - radial-medial crossvein, $t_{1}$ - fore tibia; $t_{2}$ - mid tibia; $t_{3}$ - hind tibia; $v i$ - vibrissal seta; $v t e$ - outer vertical seta; $v t i$ - inner vertical seta. The name of the country for which a particular species is reported for the first time is provided with an asterix $\left(^{*}\right)$.

\section{Key to genera of the subtribe Apodacrina}

1. orb seta-like, numerous (10-40), arranded as a tuft in posterior part of parafrontalia (figs 20, b-d). Vibrissal angle placed above oral margin, lunula in lower part strongly narrowed (fig. 21, d). ơ: $t_{2}$ and often $f_{2}$ with a ctenidium consisting of strong thick spine-like setae (figs 20, e; 22, e)......

Xerophilomyia Rohdendorf, 1925

- Proclinate orb absent or arranged as a row with 1-6 setae. Vibrissal angle placed at oral margin, lunula in lower part not narrowed. o: legs without ctenidium.

2. Proclinate orb absent or present as $1-2$ fine setae (figs $13, \mathrm{~b}-\mathrm{d}$ ). Postpedicel $4-10 \times$ as long as pedicel..... Xeromyia Rohdendorf, 1925

Proclinate orb present as 3-6 pairs of strong setae (figs 1, c; 2, c). Postpedicel 3-5 $\times$ as long as pedicel (figs $1 \mathrm{~d} ; 2 \mathrm{~d})$. Apodacra Macquart, 1854

\section{Genus Apodacra Macquart, 1854}

Apodacra Macquart, 1854: 425. Type species: Apodacra seriemaculata Macquart, 1854, by monotypy. Apodacra: Nandi, 2002: 77 (review of Hindustan species); Povolný \& Verves, 1997: 80 (review); Rohdendorf, 1925: 63 (review); 1930: 12, 18 (revision); 1970: 627 (in key), 629 (key to species);_Rohdendorf \& Verves, 1980: 462 (in key); Séguy, 1941: 251 (review of West Palaearctic species); Townsend, 1938: 99 (diagnose); Venturi, 1960: 34 (review of European species); Verves, 1986: 68 (catalog); 1990: 538 (key to East Palaearctic species); Verves et al., 2015: 265 (review); Zerova et al., 2006: 88 (in key), 95 (key to Ukrainian species).

Parapodacra Rohdendorf, 1925: 68 (as subgenus of Apodacra Macquart, 1854). Type species: Apodacra chrysocephala Rohdendorf, 1925, by designation of Townsend, 1935: 203.

Diagnosis. Small, rarely medium-sized (3.0-6.5 mm) bright colored flies. Frons and face broad, vibrissal angle placed at oral margin, head in profile angular; posterior border of head distinctly shortened; orb 1-2+2-6, strong; postpedicel $3-5 \times$ as long as pedicel.

Distribution and diversity. 16 species distributed in Palaearctic, Oriental and Afrotropical Regions.

\section{Key to species}

1. All abdominal tergites shining black, with narrow stripe of light dusting near fore margin (fig. 7, f). Oral setae black, anterior part of gena with black setulae (figs $7, \mathrm{~b}-\mathrm{c}$ ). $4.5 \mathrm{~mm}$. A. melanura sp. $\mathrm{n}$. Abdominal tergites not entirely black, with shining black spots in posterior half (figs 1, b; 3, g; 4, b; 5, f; $6, \mathrm{f} ; 8, \mathrm{~g} ; 9, \mathrm{~b} ; 10, \mathrm{f} ; 11, \mathrm{~b})$.

2. Apart from avi, other oral setae absent (figs 1, c-d; 2, c-d; 5, b-c; 10, b-c; 11, c-d). Gena with yellow setae.

Apart from $v i$, at least one black oral seta present (figs 3, b-c; 4, c-d; 6, b-c; 8, b-c; 9, c-d). ................5

3. Arista widened in basal 0.4-0.5 (figs 1, c; 2, c). Facials strongly narrower than frons (figs 1, d; 2, d-e). O': wing with cell $r_{2+3}$ entirely, cells $r_{1}, r_{4+5}$ and $d m$ partly fumose (fig. $1, \mathrm{f}$ ), fore $5^{\text {th }}$ tarsomere with long $\mathrm{d}$ (fig. 1, e). 4.5-6.5 mm. 
- $\quad$ Arista widened in basal 0.6-0.8 (figs 5, b; 11, b-c). Facials almost as wide as frons (figs 5, c; 10, c; 11, d). o: wing hyaline, without darkened areas (figs 5 , a; 10, f; 11, e).

4. The distance between median spot of $4^{\text {th }}$ abdominal tergite and each lateral stripe more than diameter of median spot; median spot of $5^{\text {th }}$ tegite much shorter than its lateral spots (fig. $5, \mathrm{f}$ ). $0^{\text {s: }}$ : hind $1^{\text {st }}$ tarsomere widened, with ventral ctenidium formed by short spine-like setae (fig. 5 , e). $5.0 \mathrm{~mm}$.

A. firanensis sp. n.

- The distance between median spot of $4^{\text {th }}$ abdominal tergite and each lateral stripes much less than diameter of median spot; all spots of $5^{\text {th }}$ tergite equal in size (fig. 10, f). $0^{\text {? }}$ : Hind $1^{\text {st }}$ tarsomere without ctenidium (fig. 10, a). 4.0-6.5 mm.

..A. seriemaculata Macquart, 1854

5. Some black setae present above $v i$ (figs $8, \mathrm{~b}-\mathrm{c} ; 9, \mathrm{c}-\mathrm{d}$ ). ơ: Fore $1^{\text {st }}-4^{\text {th }}$ tarsomeres with numerous elongate, erect d (fig. 8, e). 4.5-6.5 mm.

A. pulchra Egger, 1861

- No black setae above vi (figs 3, b-c; 4,c-d). o': Fore tarsus without long erect setae, normal setae only (figs 3, a; 6, a).....

6. Gena with black setae (figs 6, b-c). o: Hind $1^{\text {st }}$ tarsomere not widened, without ventral ctenidium (fig. 6 a). $4.5 \mathrm{~mm}$ A. idiopatica sp. $\mathrm{n}$.

- Gena with yellow setae (figs 3, b; 4, c). $0^{\text {: }}$. Hind $1^{\text {st }}$ tarsomere widened, with ventral ctenidium (fig. 3, e). .....7

7. Ground color of abdomen silver-white (figs 3, g; 4, b). $4.5-6.5 \mathrm{~mm}$. A. dispar Villeneuve, 1916

- Ground color of abdomen orange-yellow. $5.0 \mathrm{~mm}$. A. radchenkoi Verves et Khrokalo, 2015
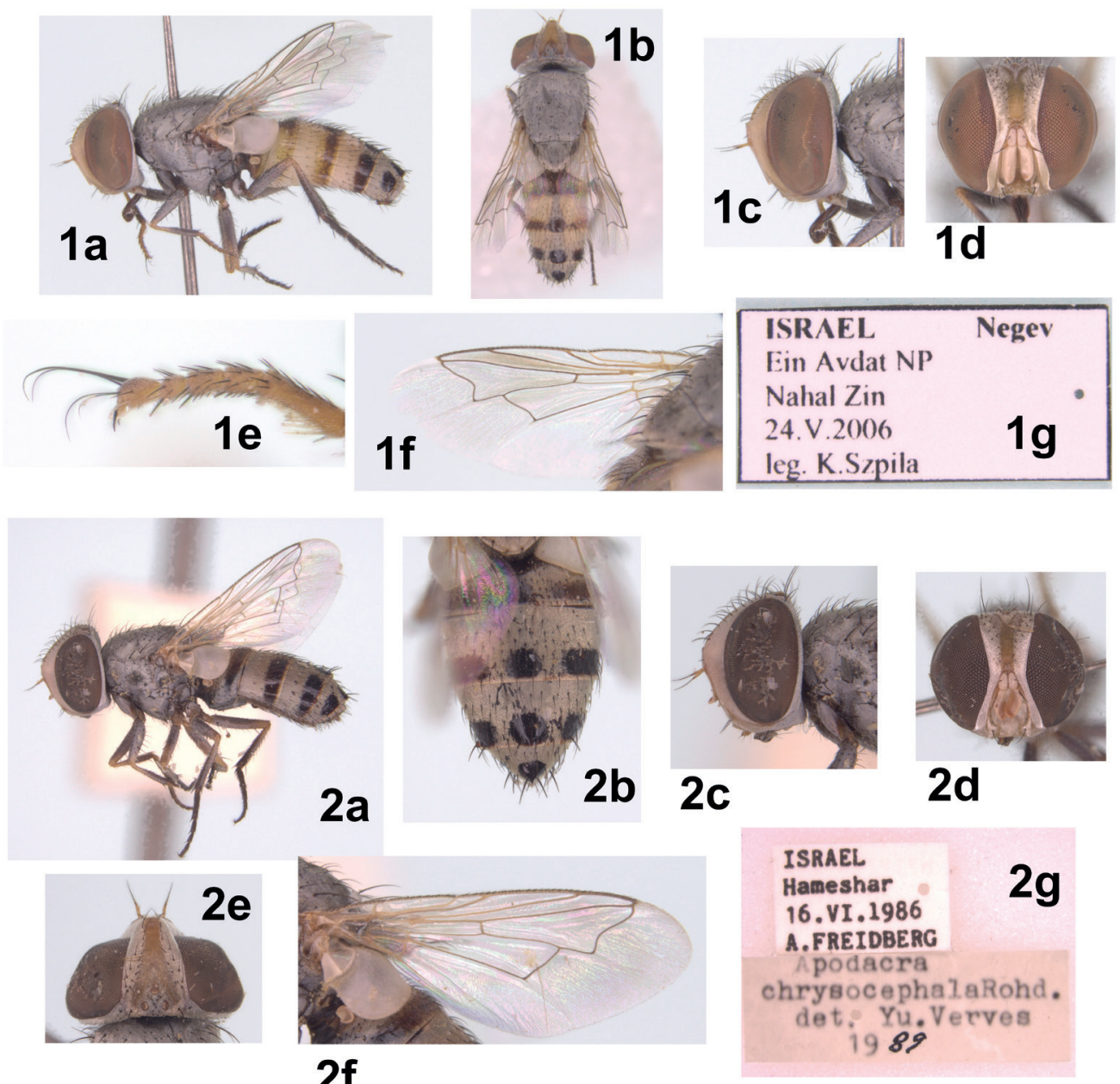

Figs 1-2. Apodacra chrysocephala Rohd.: 1 (male): a - habitus in lateral view; b - habitus in dorsal view; $\mathrm{c}$ - head in profile; $\mathrm{d}$ - head in frontal view; $\mathrm{e}-$ fore leg in anterior view; $\mathrm{f}$ - wing; $\mathrm{g}$ - label. 2(female): $\mathrm{a}-$ habitus in lateral view; $\mathrm{b}-$ abdomen in dorsal view; $\mathrm{c}-$ head in profile; $\mathrm{d}$ - head in frontal view; $\mathrm{e}-$ head in dorsal view; $\mathrm{f}$ - wing; $\mathrm{g}$ - label. 


\section{Apodacra chrysocephala Rohdendorf, 1925 (figs 1-2)}

Apodacra chrysocephala Rohdendorf, 1925: 69; 1930: 19 (redescription, faunistics); Rohdendorf \& Verves, 1980: 497 (faunistics); Verves, 1984: 538 (faunistics); 1986: 68 (catalog); 1990: 539 (in key); Verves \& Khrokalo, 2018 (Supplementary Material): 20 (faunistics); Verves et al. 2015: 267 (review).

Apodacra poeciloptera Rohdendorf, 1927: 167.

Apodacra seriemaculata: Szpila, 2010: 25 (morphology of $1^{\text {st }}$ instar larva).

Material. Israel: 3 o, Hameshar, 16.06.1986, leg. A. Freidberg (TAU). 2 o, Be`er Meshash, 21. 06. 1986, leg. A. Freidberg (TAU). 1 o, S. Palestine, Dunes Ein Rhadian, 1.05.1954, leg. O. Theodor (TAU). 1 ○, Shefech Zohar, 6.04.1988, leg. F. Kaplan (TAU). 1 ơ, Makhtech Ramon NR, Nahal Ramon, 19-20.05.2004, leg. K. Szpila (PCV). 1 o, Nahal Secher, 19.07.1984, leg. M. Kaplan (TAU). 1 ○’, Negev, dunes along Nahal Sekher, n. Ramat Khovav, 13.05.2006 leg., K. Szpila (PCV). $10^{\prime \prime}$, Zin Wilderness, Nahal Zin at En Akrabim, cane-covered sandy wadi el, $-61 \mathrm{~m},\left(30^{\circ} 53^{\prime} 38^{\prime \prime} \mathrm{N}, 35^{\circ} 09^{\prime} 39^{\prime \prime} \mathrm{E}\right), 10.04 .1995$, leg. M. E. Irwin (TAU). 1 o, Arava Valley, Iddan, wadi running east of date palm orchard, $-110 \mathrm{~m}\left(30^{\circ} 48^{\prime} 93^{\prime \prime} \mathrm{N}, 35^{\circ} 16^{\prime} 79^{\prime \prime} \mathrm{E}\right), 24.03 .1995$, leg. M. Irwin (NHMUK). $20^{\circ}$, Arava Valley, Shizaf Nature Reserve, Hazeva, north of water treatment plant low sandy hummocks in small wadi el, $-80 \mathrm{~m}\left(30^{\circ} 46^{\prime} 01^{\prime \prime} \mathrm{N}, 35^{\circ} 15^{\prime} 37^{\prime \prime} \mathrm{E}\right), 24.03 .1995$, leg. Irwin. 1 o, Negev, Ein Avdat, NP Nahal Zin, 17.05.2006, leg. K. Szpila (PCV). 1 ф, Ezuz, 15.08.1984, leg. I. Nussbaum (TAU). 1 ơ, Yeruham, 26.04.1973, leg. M. Kaplan (TAU). 1 , Dead Sea, Wadi Deyal, 10.05.1958, leg. O. Theodor (TAU). 1 \&, Elifaz, sewage, 5.04.1997, leg. A. Freidberg (TAU). Egypt: 1 o, Sinai: Firan, 9.04.1973, leg. A. Freidberg (TAU). 1 \%, St. Katharina, 18.07.1974, leg. F. Kaplan (TAU).

Distribution: Palaearctic: Asia: Egypt (Sinai), Israel, Kyrgyzstan, Tajikistan, Turkmenistan, Uzbekistan, Mongolia, China (Gansu, Neimenggu).

Habits: Adult flies prefer sandy areas.

\section{Apodacra dispar Villeneuve, 1916 (figs 3-4)}

Apodacra dispar Villeneuve, 1916: 507; Holstein \& Rudzinsky, 1994: 114 (habits, faunistics); Pape, 1988: 8 (revision of type); Piwczyński et al., 2017: 53, 57 (in dendrograms); Szpila, 2010: 23 (morphology of $1^{\text {st }}$ instar larva); Verves et al., 2015: 267; 2017: 133 (faunistics); Verves \& Khrokalo, 2014: 12 (habits, faunistics); 2018 (Supplementary Material): 20 (faunistics); Zerova et al., 2006: 96 (in key); Zumpt, 1961: 117 (revision of type and faunistics).

Apodacra rondaniella Venturi, 1957: 157; 1960: 35 (in key); Pape, 1988: 8 (type revised); 38 (taxonomy, faunistics); Verves, 1986: 68 (catalog).

Apodacra cyprica: Séguy, 1941: 251 (redescription and faunistics); misidentification, not cyprica Rondani, 1859.

Material. Israel: 1 ○, Akko, 4.10.1970, leg. A. Freidberg (TAU). 1 ᄋ, Herzliyya Beach, 12.10.1986, on dead fish, leg. A. Freidberg (TAU). 1 \&, W. Faria, 1.06.1971, leg. J. Kugler (TAU). 1 ơ, Dunes Ashqelon, Coakepst Plain, 25.04.1954, leg. O. Theodor (TAU). 1 ơ, Mizpe Shalem Palms, South 9.04.1986, leg. A. Shlagman (TAU). 1 \&, Nahal Bsor, 19.07.1984, leg. F. Kaplan. 1 ơ, Sede Boqer, 2.06.1953, leg. O. Theodor (TAU). 1 \&, Ein Aqev, 8.08.1977, leg. A. Freidberg (TAU). 1 \&, Farael, 28.04.1976, leg. M. Kaplan (TAU). 1 o, Ramon, 4.08.1970, leg. J. Kugler (TAU). 1 O’, Rt. 171, 3 km W of Bor Loz, 8.05.2003, leg. A. Freidberg (TAU).

Distribution: Palaearctic: Europe: Spain, France, Italy, Greece, Czech Republic (Moravia), Ukraine; Asia: Israel*, Turkey, Kyrgyzstan, Tajikistan, Turkmenistan, Uzbekistan. Afrotropical: Angola, South Africa, Tanzania, Zimbabwe.

Habits: Adult flies prefer sandy areas. Larvae were found in a dead specimen of the grasshopper Eyprepocnemis plorans (Charpentier) (Holstein \& Rudzinski, 1994).

\section{Apodacra firanensis Verves et Khrokalo, sp. n. (fig. 5)}

Material. Type. Holotype: ${ }^{\nwarrow 7}$ : Egypt: Sinai, Firan, 9.04.1973, leg. A. Freidberg. Deposited in TAU.

Differential diagnosis: Similar to A. dispar Villeneuve, 1916 by the structure of hind tarsi and head proportions, differing by the absence of $v t e$, undeveloped oral setae, elongate postpedicel, yellow fore tarsi and partial reduction of abdominal pattern.

Male. Body length $5.0 \mathrm{~mm}$. - Head (figs 5, b-d). Head densely silvery white pollinose, frontal vitta light yellow, almost without dusting, occiput and gena light grey pollinose, antenna and palp yellow, apex of arista fuscous. Frons at vertex $0.36 \times$, at level of antennal base $0.35 \times$ head-width. Frontal vitta $1.5 \times$ widened backwards, at level of fore orb equal in length to parafrontalia. Postpedicel $3,7 \times$ as long as pedicel, arista widened in basal $2 / 3$. 


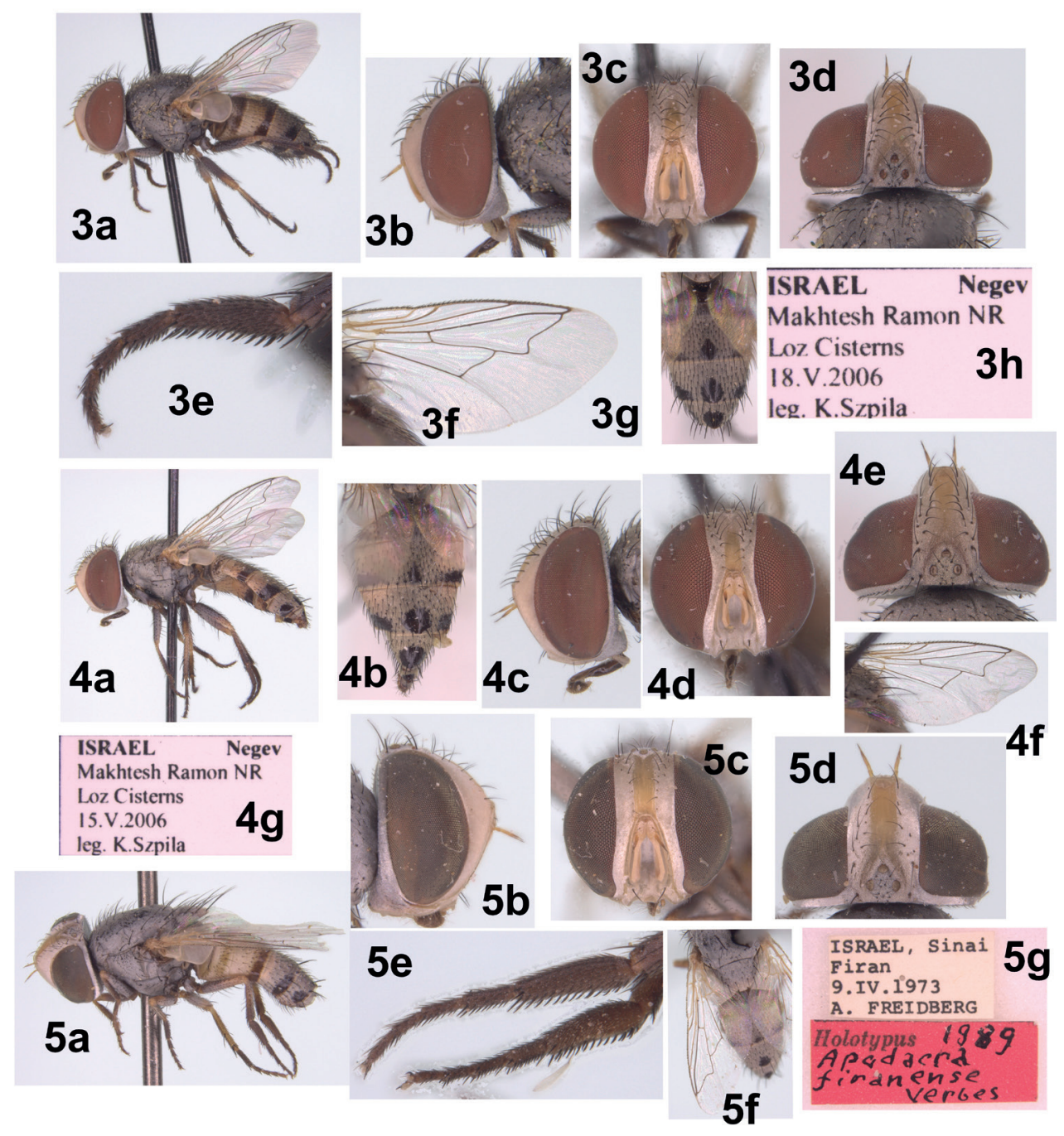

Figs 3-4. Apodacra dispar Vill.: 3 (male): a - habitus in lateral view; b - head in profile; $\mathrm{c}$ - head in frontal view; $\mathrm{d}$ - head in dorsal view; $\mathrm{e}$ - hind leg in anterior view; $\mathrm{f}$ - wing; $\mathrm{g}$ - abdomen in dorsal view; $\mathrm{h}$ - label. 4 (female): $\mathrm{a}-$ habitus in lateral view; $\mathrm{b}$ - abdomen in dorsal view; $\mathrm{c}$ - head in profile; $\mathrm{d}-\mathrm{head}$ in frontal view; $\mathrm{e}$ - head in dorsal view; $\mathrm{f}$ - wing; $\mathrm{g}$ - label.

Fig. 5. Apodacra firanense sp. n. (male): a - habitus in lateral view; b - head in profile; $\mathrm{c}-$ head in frontal view; $\mathrm{d}$ - head in dorsal view; e - hind legs in anterior view; $\mathrm{f}$ - wing \& abdomen in dorsal view; $\mathrm{g}$ - label.

Parafacialia at level of antennal base $0.22 \times$, gena $0.11 \times$ eye-height. Palp at apex widened. oc fine, seta-like; vte absent; orb 1+2-3, medium long; fr 7-8, long and fine; parafrontalia and parafacialia with microscopic light setae; gena with erect yellow setae; only one pair of vi present; oral setae absent. - Thorax (fig. 5, a) covered with long black setae, light grey pollinose, longitudinal stripes of mesonotum poorly developed; tip of scutellum yellowish; acr $0+1$; $d c 0+1$; ia 1+1; pprn 2; npl 2 (with several setulae); kepst $1+1$. Scutellum with 3 pairs of long and strong marg; $d s$ seta-like. - Wing (figs $5 \mathrm{a}, \mathrm{f}$ ) hyaline. Petiolus of vein $R_{4+5} 0.5 \times$ as long as $r-m$, vein $R_{4+5}$ with one basal seta, vein $M$ right-angled, $d m$-cu s-like curved. - Legs (figs 5, a, e). All femora grey pollinose, in distal parts yellow, tibia yellow, $t_{1}$ and $t_{3}$ exteriorly grey pollinose, fore tarsi yellow, other tarsi entirely dark brown. First tarsomere of hind tarsus widened, with ctenidium of short and thick ventral spine-like setae. $t$, with one ad. - Abdomen (fig. 5, f) densely light yellowish grey pollinose, pattern partly reduced; $1+2^{\text {nd }}$ tergite anteriorly fuscous; $3^{\text {rd }}$ tergite with a mark of dark median spot in hind 0.4 and 
paired shining yellowish brown lateral stripes; $4^{\text {th }}$ tergite in hind 0.3 with black median spot and paired lateral stripes, the distance between spot and stripes more than diameter of spot; $5^{\text {th }}$ tergite with black median spot in hind 0.5 and paired lateral stripes in hind $0.6-0.7$; $6^{\text {th }}$ tergite with small shining black median spot. $1+2^{\text {nd }}$ and $3^{\text {rd }}$ abdominal tergites without medio-marginal setae. Terminalia black, light pollinose.

Female. Unknown.

Etymology: The species epithet is formed from the name of the type locality, Firan.

Distribution: Palaearctic: Asia: Egypt (Sinai).

Apodacra idiopatica Verves et Khrokalo, sp. n. (fig. 6)

Material. Type. Holotype: ơ: Israel: Ma`agan Mikha`el, 11.06.1985, leg. J. Kugler. Deposited in TAU.

Differential diagnosis: Similar to A. dispar Villeneuve, 1916 in the presence of black oral setae and shortened postpedicel, differing by the black setae of gena and the absence of ctenidium on $0^{\mathrm{T}}$ hind tarsi.

Male. Body length $4.5 \mathrm{~mm}$. - Head (figs 6, b-d). Head yellowish silver pollinose, frontal vitta in fore $2 / 3$ yellow, almost without dusting, antenna and palp yellow, apical part of arista blackish. Frons at vertex $0.43 \times$, at level of antennal base $0.33 \times$ head-width. Frontal vitta $3.5 \mathrm{x} \times$ widened backwards, at level of fore orb $0.6 \times$ as wide as parafrontalia. Postpedicel $2.2 \times$ as long as pedicel, arista widened in basal 0.6. Parafacialia at level of antennal base $0.20 \times$, gena $0.07 \times$ eye-height. Palp medium long, at apex widened. One regular row of porb; vte fine, $0.5 \times$ as long as $v t i$; oc seta-like; fr 9-10, mid-long, in fore part of frons crossed; orb 1+3, strong; parafrontalia and parafacialia with microscopic yellow setae; below of $v i$ several fine black oral setae present; gena in fore part with several black setae; hind part of gena and lower part of occiput with yellow setae. - Thorax (fig. 6, a) covered with short black setae, densely light grey pollinose, longitudinal stripes of mesonotum absent, scutellum entirely yellowish; acr $0+1 ; d c 2-3+4$, only hind pair strong; ia $0-1+1 ;$ pprn $2 ; n p l$ 2 (without setulae); kepst 1+1, katepisternum setaly. Scutellum with 3 pairs of strong marg, $d s$ badly developed. - Wing (fig. 6, e) hyaline, basicosta and epaulett yellow. The petiolus of vein $R_{4+5} 0.3 \times$ as long as $r-m$, vein $R_{4+5}$ bare, vein $M$ right-angled, $d m$-cu s-like curved, the ratio of $3^{\text {rd }}$ and $5^{\text {th }}$ costal sections is $1: 2.5$. - Legs (fig. 6, a) grey, knees yellow. $2^{\text {nd }}-$ $4^{\text {th }}$ tarsomeres of fore tarsi shortened, with numerous short $d$; $t_{2}$ with one long and one short ad. Hind tarsi without ctenidium. - Abdomen (figs 6 , a, f) densely yellowish grey pollinose. $1+2^{\text {nd }}$ and $3^{\text {rd }}$ tergites without medio-marginal setae. $1+2^{\text {nd }}$ tergite with brownish median spot and widened brownish black lateral stripes; $3^{\text {rd }}$ tergite in hind 0.3 with small black median spot and brownish black lateral stripes, the distance between elements of pattern more than diameter of median spot; $4^{\text {th }}$ tergite with similar black pattern in hind 0.4 , but the distance between elements equal to diameter of median spot; $5^{\text {th }}$ tergite in hind $2 / 3$ with 3 black spots. Terminalia black, densely light pollinose.

Female. Unknown.

Etymology: The species epithet is an adjective formed from the Greek words, idios peculiar, and pathos - suffering; in the medical literature this word refers to the phenomenon of unknown origin of some feature.

Distribution: Palaearctic: Asia: Israel.

Apodacra melanura Verves et Khrokalo, sp. n. (fig. 7)

Material. Type. Holotype: o: Israel: Ein Zik, 8.08.1977, leg. A. Freidberg. Deposited in TAU.

Differential diagnosis: Similar to the Afrotropical A. natalensis Villeneuve, 1916 in the abdominal pattern and black tarsi, differing by the absence of reddish abdominal spots and black setae on gena.

Fe male. Body length $4.5 \mathrm{~mm}$. - Head (figs 7, b-d). Parafrontalia, facialia and gena densely silvery light pollinose, frontal vitta yellow, almost without dusting, antenna yellow, 
dark grey pollinose, apical part of arista black, palp yellow, occiput grey pollinose. Frons at vertex $0.34 \times$, at level of antennal base $0.31 \times$ head-width. Frontal vitta $1.8 \times$ widened backwards, at level of fore orb 1.1-1.4× as wide as one of parafrontalia. Postpedicel $3.3 \times$ as long as pedicel, arista widened in basal $2 / 3,2^{\text {nd }}$ aristomere $2 \times$ as long as wide. Parafacialia at level of antennal base $0.20 \times$, gena $0.06 \times$ eye-height. Palp long, at apex widened. One regular row

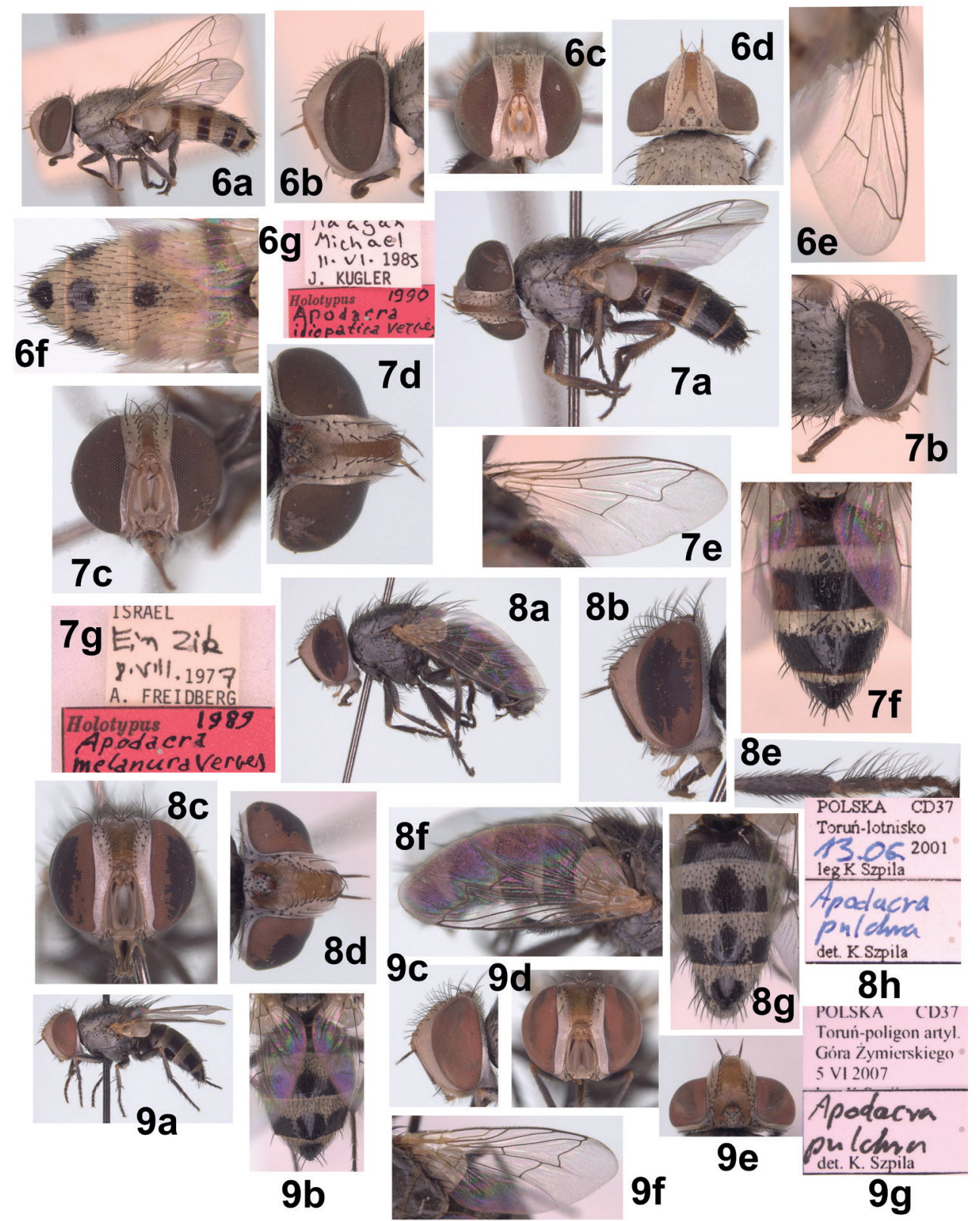

Fig. 6. Apodacra idiopatica sp. n. (male): a - habitus in lateral view; b - head in profile; $\mathrm{c}-$ head in frontal view; $\mathrm{d}$ - head in dorsal view; $\mathrm{e}$ - wing; $\mathrm{f}$ - abdomen in dorsal view; $\mathrm{g}$ - label.

Fig. 7. Apodacra melanura sp. n. (female): a - habitus in lateral view; b - head in profile; $\mathrm{c}$ - head in frontal view; $\mathrm{d}$ - head in dorsal view; e - wing; $\mathrm{f}$ - abdomen in dorsal view; $\mathrm{g}$ - label.

Figs 8-9. Apodacra pulchra Egger. 8 (male): a - habitus in lateral view; b - head in profile; $\mathrm{c}$-head in frontal view; $\mathrm{d}$-head in dorsal view; $\mathrm{e}-$ fore leg in posterior view; $\mathrm{f}-$ wing and abdomen in lateral view; $\mathrm{g}-$ abdomen in dorsal view; $\mathrm{h}$ - Label. 9 (female): $\mathrm{a}$ - habitus in lateral view; $\mathrm{b}$ - abdomen in dorsal view; $\mathrm{c}-$ head in profile; $\mathrm{d}$-head in frontal view; $\mathrm{e}-$ head in dorsal view; $\mathrm{f}-$ wing; $\mathrm{g}$ - label. 
of porb; vte strong, $0.5 \times$ as long as $v t i$; oc strong and long; fr 8 , strong and crossed; orb $1+5$, long and strong; parafrontalia and parafacialia with microscopic light setae, $v i$ strong and distinctly longer than 5 pairs of black oral setae; gena in fore part with black setae, in hind one with yellow setae. - Thorax (fig. 7 a) covered with long and strong black setae, yellowish grey pollinose, longitudinal stripes badly developed, apex of scutellum reddish. acr $0+1-2$; dc $0-1+5-6$, only 2 hind pairs strong; pprn $2 ; n p l 2$ (without setulae); ia $1+2$. Scutellum with 3 pairs of long marg, $d s$ badly developed. $t_{2}$ with one $a d$. - Wings (fig. 7, e) hyaline. The petiolus of vein $R_{4+5} 0.5 \times$ as long as $r-m$, vein $R_{4+5}$ with $2-3$ black basal setae, vein $M$ acuteangled, $d m$-cu slightly curved, almost straight. - Legs (fig. 7, a). All femora grey, at apex yellow, all tibia yellow, $t_{1}$ and $t_{2}$ in apical parts fuscous, all tarsi brownish black. - Abdomen (figs $7, a, f) .1+2^{\text {nd }}$ abdominal tergite entirely blackish brown; $3^{\text {rd }}$ and $4^{\text {th }}$ tergites in hind $2 / 3$ shining black, in fore $1 / 3$ densely silvery white pollinose; $5^{\text {th }}$ tergite in hind $3 / 4$ shining-black. Male. Unknown.

Etymology: The species epithet is a noun in apposition formed from the Greek words melanos - black and ura - tail.

Distribution: Palaearctic: Asia: Israel.

\section{Apodacra pulchra Egger, 1861 (figs 8-9)}

Apodacra pulchra Egger, 1861: 216; Piwczyński et al., 2017: 53, 57 (in dendrograms); Povolný \& Verves, 1997: 80 (redescription, habits, faunistics); Rohdendorf, 1930: 19 (redescription, faunistics); 1970: 639 (in key); Séguy 1941: 256 (redescription, faunistics); Szpila, 2010: 24 (morphology of $1^{\text {st }}$ instar larva); Szpila \& Pape, 2005: 293 (larval morphology); Venturi, 1960: 34 (in key), 36 (morphology, faunistics); Verves, 1986: 68 (catalog); Verves \& Khrokalo, 2014: 12 (habits, faunistics); 2018 (Supplementary Material): 20 (faunistics); Verves et al., 2015: 268 (review); 2018: 99 (faunistics); Zerova et al. 2006: 96 (in key).

Material. Israel: 1 ơ, Mt. Hermon (1500 m), 8.08.1974, leg. A. Freidberg (TAU).

Distribution: Palaearctic: South and Central Europe; Asia: Israel, Turkey, Tajikistan, China (Neimenggu).

Habits: Flies prefer sandy areas.

\section{Apodacra seriemaculata Macquart, 1854 (figs 10-11)}

Apodacra seriemaculata Macquart, 1854: 426; Gorobchishin, 2006: 111 (habits); Piwczyński et al., 2017: 53, 57 (in dendrograms); Rohdendorf, 1930: 19 (redescription); 1970: 639 (in key); Séguy, 1941: 257 (redescription); Venturi, 1960: 35 (in key), 38 (review); Verves, 1986: 68 (catalog); Verves \& Khrokalo, 2014: 12 (habits, faunistic); 2018 (Supplementary Material): 4 (faunistic); Verves et al., 2015: 269 (review); 2018: 99 (faunistic); Zerova et al., 2006: 95 (in key).

Material. Israel: 1 \&, Palestine, Tantura, 16.08.1954, leg. O. Theodor (TAU). 1 \&, Nahal Alexander, 6.07.1996, leg. R. Hoffman (TAU). 1 o', Lakhish, 9.09.1970, leg. A. Freidberg (TAU). 1 o', 1 o, Sheluhat Qadesh Barnea', 7.05.1998, leg. A. Freidberg (TAU). 3 o', Negev, Makhtech Ramon NR, Loz Cisterns, 18. and 23.05.2006, leg. K. Szpila (PCV). 1 o, Dunes Ache, 18.09.1954, leg. O. Theodor (TAU). 1 o, S. Palestine, Tel Faza, Wadi Shall, 21.05.1953, leg. O. Theodor (TAU). 1 \%, Coakepst plain, Nathalia, 28.08.1953, leg. O. Theodor (TAU). 1 \&, Tell Far'a, 21.05.1953, leg. J. Wahram (TAU). 1 o, Taba, 27.04.1974, leg. A. Freidberg (TAU).

Distribution: Palaearctic: South Europe; Asia: Turkey, Israel, Iran, United Arab Emirates, Turkmenistan.

Habits: Psammophilous and xerophilous species. Larvae were found in a nest of the sphecid wasp Tachysphex panzeri (Vander Lind.) provisioned by paralyzed acridids (Grandi, 1961).

\section{Genus Xeromyia Rohdendorf, 1925}

Xeromyia Rohdendorf, 1925: 70 (as subgenus of Apodacra Macquart, 1854). Type species: Apodacra xanthopoda Rohdendorf, 1925, by designation of Townsend, 1938: 152.

Xeromyia: Rohdendorf, 1930: 16, as a subgenus of Apodacra Macquart, 1854 (revision); Rohdendorf \& Verves, 1980: 493 (key); Verves, 1986: 85 (catalog); 1990: 539 (key to East Palaearctic species); Verves et al., 2015: 270 (review). 


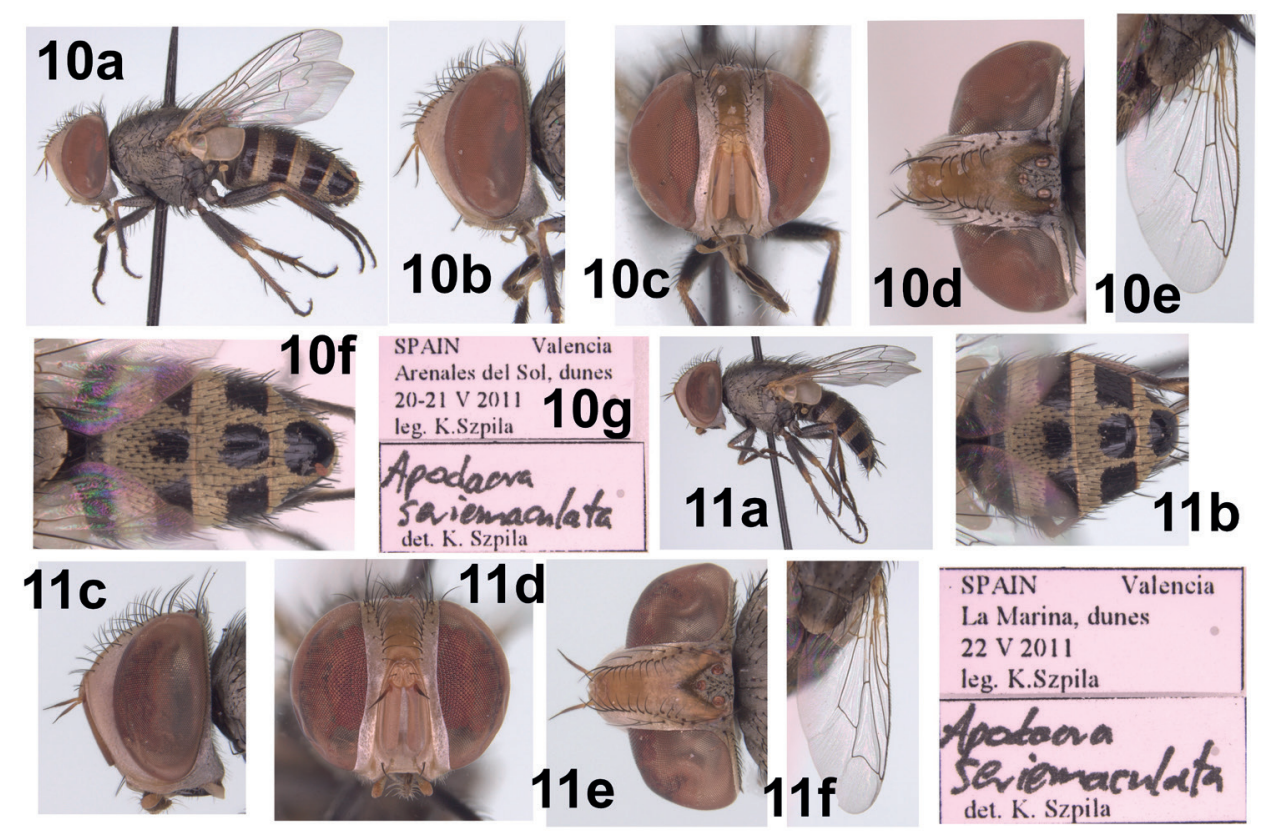

Figs 10-11. Apodacra seriemaculata Mcq.: 10 (male): a -habitus in lateral view; b - head in profile; c -head in frontal view; $\mathrm{d}$ - head in dorsal view; e - wing; $\mathrm{f}$ - abdomen in dorsal view; $\mathrm{g}$ - label. 11 (female): a habitus in lateral view; $\mathrm{b}-$ abdomen in dorsal view; $\mathrm{c}$ - head in profile; $\mathrm{d}$-head in frontal view; $\mathrm{e}$ - head in dorsal view; f - wing; g - label.

Diagnosis. Small or medium sized (3.5-9.5 mm) bright colored flies. Frons and face of medium width, vibrissal angle placed at oral margin, head in profile angular; hind border of head slightly shortened; orb 1+0-2; Postpedicel 3-10× as long as pedicel.

18 species are distributed in southern part of Palaearctic and Afrotropical Regions. Larvae of Xeromyia sp. were bred from nests of sphecid wasp Tachysphex pompiliformis (Panz.) where feed by paralyzed locust Dociostaurus kraussi Ingen. (Malkovsky, 1962).

\section{Key to species}

1.

2. 2 pairs of $v i$. Frons as wide as eye, $0.30 \times$ head-width, frontal vitta in fore part parallel, in the middle of frons $1.5 \times$ as wide as one of parafrontalia, $1.5 \times$ widened in hind part. Abdomen reddish yellow, 3rd and 4th tergites with brown median spots, $5^{\text {th }}$ tergite with 3 spots. $6.0-8.0$ mm.

$X$. algiralis (Séguy, 1941)

- One pair of vi. ... 3

3. 2 pairs of proclinate orb (figs $15, \mathrm{~b}-\mathrm{c} ; 16, \mathrm{~b}-\mathrm{c}$ ). Frontal vitta in fore part strongly narrowed, narrower than one of parafrontalia. $4.5-5.0 \mathrm{~mm}$. X. merei (Séguy, 1941) One pair of proclinate orb or they absent (figs 17, b-c; $18, \mathrm{c}-\mathrm{d}$ ). $4^{\text {th }}$ abdominal tergite in hind part shining black. $5.0-5.5 \mathrm{~mm}$ X. sulcata (Villeneuve, 1933) $4^{\text {th }}$ tergite with another pattern, sometimes entirely black.

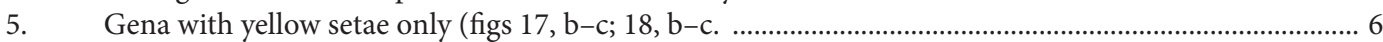

- Fore part of gena with several black setae in addition to yellow ones. .................................................. 13

6. Pleuron and legs entirely yellow. 4.5-5.5. mm.................................... X. xanthopoda (Rohdendorf, 1925)

- $\quad$ Pleuron grey pollinose, legs as a rule partly dark pollinose.

7. $\quad 3^{\text {rd }}-5^{\text {th }}$ abdominal tergites entirely black, slightly light pollinose. $4.0 \mathrm{~mm}$..................... omanica sp. n.

- $\quad 3^{\text {rd }}-5^{\text {th }}$ tergites with dark spots and stripes, densely light pollinose.

8. $\quad 3^{\text {rd }}$ tergite in hind part entirely shining black. 4.0-6.5 $\mathrm{mm}$.......

- $\quad 3^{\text {rd }}$ tergite in hind part with distinctly separated median spot and lateral stripes. 
9. Frontal vitta in fore part $0.5 \times$ as wide as one of parafrontalia. The distance between lateral stripes and median spot of $3^{\text {rd }}$ abdominal tergite very narrow, almost linear. 6.5-7.0 mm. Saudi Arabia.

..X. jeddaense sp. $\mathbf{n}$.

Frontal vitta in fore part not less than $0.7 \times$ as wide as one of parafrontalia (fig. 12, d). The distance between spot and stripes of $3^{\text {rd }}$ abdominal tergite broad, only slightly less than diameter of median spot.

10. Lateral bands of $4^{\text {th }}$ and $5^{\text {th }}$ abdominal tergites black (fig. 12, b) . 4.5-5.5 mm.

X. africana (Rohdendorf, 1930)

- Lateral bands of $4^{\text {th }}$ and $5^{\text {th }}$ abdominal tergites brownish yellow. 4.5-7.0 mm.

11. $4^{\text {th }}$ abdominal tergite with dark median spot and lateral stripes

X. pseudoxygona (Rohdendorf, 1925)

$4^{\text {th }}$ tergite with median spot only, lateral stripes absent. 5.0-5.5 mm. X. ponti sp. $\mathbf{n}$.

12. $4^{\text {th }}$ and $5^{\text {th }}$ abdominal tergites with dark brown to black median spot and brownish yellow lateral stripes. $4.0-5.5 \mathrm{~mm}$. X. orthogona (Rohdendorf, 1925)

Pattern of $4^{\text {th }}$ and $5^{\text {th }}$ tergites completely black. $5.0 \mathrm{~mm}$. ........................................ . moderabilis sp. $\mathbf{n}$.

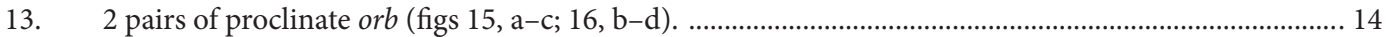

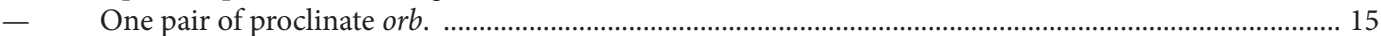

14. Gena in fore part with yellow setae only. ................................................................ X. merei (Séguy, 1941)

- Gena in fore part with several black setae. $4.5 \mathrm{~mm}$...................................................... X. nahalica sp. n

15. Abdomen with linear longitudinal median black stripe (fig. 13, f). ................................................... 16

- Abdominal tergites with broad median spots and lateral stripes in hind parts. .................................... 17

16. Abdomen densely golden grey pollinose, lateral spots of $4^{\text {th }}$ tergite well developed,black. $t_{1}$ in apical $2 / 3$ black. ................................................................................................... X. orthogona (Rohdendorf, 1925)

Abdomen orange yellow, with fine light dusting, lateral spots of $4^{\text {th }}$ tergite almost reduced, brownish yellow. $t_{1}$ entirely yellow ......................................................................................................... ponti sp. n.

17. $\quad 3^{\text {rd }}$ abdominal tergite in hind part entirely shining black (fig. 17, f) .... X. stenorhina (Rohdendorf, 1934)

$3^{\text {rd }}$ abdominal tergite with median spot and separated with it paired lateral stripes. ............................. 18

18. In addition to usual pattern, $3^{\text {rd }}$ abdominal tergite with a pair of lateral black setaed areas in hing part. 5.5-7.0 mm...................................................................................... X. dasystigma (Rohdendorf, 1934)

$3^{\text {rd }}$ abdominal tergite without black setaed areas.

19. Pleuron and legs entirely yellow. X. xanthopoda (Rohdendorf, 1925)

Pleuron and legs distinctly light grey pollinose.

20. Lateral spots of $1+2$ abdominal tergite brownish black (figs 12, a-b). ..... africana (Rohdendorf, 1930)

- Lateral spots of $1+2$ abdominal tergite brownish yellow..... X. pseudoxygona (Rohdendorf, 1925)

Xeromyia africana (Rohdendorf, 1930) (fig. 12)

Apodacra (Xeromyia) africana Rohdendorf, 1930: 16.

Xeromyia africana: Koçak \& Kemal, 2015: 352 (faunistics); Rohdendorf \& Verves, 1980: 497 (in key); Verves, 1986: 85 (catalog); Verves \& Khrokalo, 2018 (Supplementary Material): 20 (faunistics); Verves et al., 2015: 270 (review).

Material. Israel: 1 o, Palestine, nr. Jerisheh, 4-7 mi NE of Jaffa, 26.04.1918, leg. E. Austen (NHMUK). (2 ơ, Berekhat Ya'ar, North, 23.05.2003, leg. A. Freidberg (TAU). 1 o, Bafjam, leg. A. Freidberg, 10.06.1985 (TAU). 1 ơ, Be`er Meshash, 17.07.1985, leg. J. Susman (TAU). 1 ơ, 1 \&, Nahal Secher, 19.07.1984, leg. M. Kaplan (TAU). 1 \&, Negev, dunes along Nahal Sekher n. Ramat Khovav, 13.05.2006, leg. K. Szpila (PCV). 1 o, Sede Boqer, 2.06.1953, leg. O. Theodor (TAU). 1 o, Hazeva Field School, 30²43' N, 35²15' E, 14.12.1997, leg. A. Maklakov (TAU). 1 đ', Elifaz, sewage, 5.04.1997, leg. A. Freidberg (TAU).

Distribution: Palaearctic: North Africa: Morocco; Asia: Israel. Habits: Psammophilous and xerophilous species.

\section{Xeromyia algiralis (Séguy, 1941)}

Apodacra algiralis Séguy, 1941: 254.

Xeromyia algiralis: Rohdendorf \& Verves, 1980: 496 (in key); Verves, 1986: 86 (catalog); Verves \& Khrokalo, 2018 (Supplementary Material): 21 (faunistic); Verves et al., 2015: 270 (review).

Material. Egypt: 1 , Siwa, 31.08.1935, leg. J. Omer-Cooper (NHMUK).

Distribution: Palaearctic: North Africa: Algeria, Egypt. 
Habits: Larvae live in nests of the eumenid wasp, Eumenes dimidiatipennis Sauss. (Séguy, 1941).

\section{Xeromyia jeddaense Verves et Khrokalo, sp. n.}

Material. Type. Holotype: ○: Saudi Arabia: nr. Jedda, 21.01.1946, leg. E. S. Brown. Deposited in NHMUK. Paratype: o: Saudi Arabia: Buraiman nr. Jedda, 18.01.1946, leg. E. S. Brown. Deposited in NHMUK.

Differential diagnosis: Similar to X. africana (Rohdendorf, 1930) and $X$. transoxiana (Rohdendorf, 1925) in coloration and abdominal pattern, differing from the former species by the fine $f r$ and narrower dusting areas between spots of $3^{\text {rd }}$ abdominal tergite, and from the latter by the very narrow fore part of frontal vitta.

Female. Body length 6.5-7.0 mm. - Head. Frontal vitta brownish yellow, almost without dusting, other parts of head densely silvery white pollinose. Antenna and palp yellow, apical half of arista darkened. Frons at vertex $0.34-0.35 \times$, at level of antennal base $0.30-0.33 \times$ head-width. Frontal vitta $3.0 \times$ widened in hind part, in fore part parallel, $0.5 \times$ as wide as one of parafrontalia. Postpedicel $3.0 \times$ as long as pedicel, arista widened in basal $0.7-0.8$. Parafacialia at level of antennal base $0.17-0.19 \times$, gena $0.04-0.06 \times$ eye-height. Palp at apex strongly widened. oc fine; fr 8-10, short and fine, not crossed; orb $1+1$, proclinate ones short; parafrontalia and parafacialia with short light setae; gena with more dense and long yellow setae and 2-3 black setae in fore part; one pair of $v i$; oral setae absent. - Thorax covered with medium long black setae, densely light grey pollinose, longitudinal stripes badly developed, the apex of scutellum light yellow. acr $0+1 ; d c 0+2-3$; ia $0-1+1-2$; pprn 2; npl 2 (without setulae). Scutellum with 3 pairs of strong marg; $d s$ not distinct. - Wings hyaline. Costal spine absent, petiolus of cell $r_{4+5} 0.5 \times$ as long as $r-m, R_{4+5}$ bare, $M$-vein rightangled, $d m$-cu s-like curved. $t_{2}$ near the middle with one elongate and one short ad. - Legs yellow; $f_{1}$ almost entirely, $f_{2}$ and $f_{3}$ in basal $2 / 3$ grey pollinose; $t_{1}$ and $t_{3}$ fuscous in basal $2 / 3$; base of $t_{3}$ grayish. - Abdomen with light yellowish grey dusting, with black pattern, slightly reddish laterally. $1+2^{\text {nd }}$ tergite entirely black, $3^{\text {rd }}$ tergite in hind $1 / 3-2 / 5$ with rectangle transverse median spot, separated from lateral stripes by narrow areas of dusting; $4^{\text {th }}$ tergite with similar pattern, but pollinose areas between spots more wide; $5^{\text {th }}$ tergite in hind 0.6 with large median spot and paired rectangle lateral spots.

Male. Unknown.

Etymology: The species epithet is formed from the name of the type locality, Jedda.

Distribution: Palaearctic: Asia: Saudi Arabia.

\section{Xeromyia moderabilis Verves et Khrokalo, sp. n.}

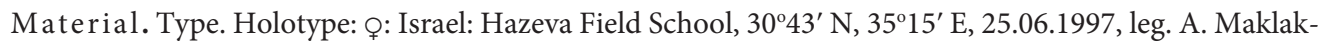
ov. Deposited in TAU.

Differential diagnosis: Similar to X. orthogona (Rohdendorf, 1925) in abdominal pattern and presence of black setae on gena, differing by entirely black pattern of $4^{\text {th }}$ and $5^{\text {th }}$ abdominal tergites.

Female. Body length $5.0 \mathrm{~mm}$. - Head. Frontal vitta brownish yellow, almost without dusting, parafrontalia, lunula, parafacialia and fore part of gena densely silvery white pollinose, hind part of gena and occiput light grey pollinose. Antenna and palp yellow, only apical narrowed part of arista darkened. Frons at vertex $0.38 \times$, at level of antennal base $0.33 \times$ head-width. Frontal vitta $1,8 \times$ widened in hind part, in the middle of frontal length $1.5 \times$ as wide as one of parafrontalia. Postpedicel $4.2-4.3 \times$ as long as pedicel, arista widened in basal 0.7-0.8. Parafacialia at level of antennal base $0.17 \times$, gena $0.09-0.10 \times$ eye-height. Palp at apex strongly widened. porb 1 row; oc midle long; $f r 7-9$, short and fine, not crossed; orb $1+1$, proclinate ones medium long; parafrontalia and parafacialia with short light setae; gena with more dense and long yellow setae and 2-3 black setae in fore part; only one pair of $v i$; oral setae absent. - Thorax covered with with medium long black setae, densely light 
grey pollinose, the apex of scutellum light yellow. acr $0+1$; $d c 1+2-3$; ia $0-1+1-2$; pprn 2 ; npl 2 (without setulae). Scutellum with 3 pairs of strong marg and one pair $d s$. - Wings hyaline. Costal spine absent, petiolus of cell $r_{4+5} 0.5 \mathrm{x}$ as long as $r-m, R_{4+5}$ bare, $M$-vein right-angled, $d m$-cu s-like curved. - Legs grey pollinose, tarsi brownish black; apical parts of $f$ and basal $0.3-0.5$ of $t$ yellow. $t_{2}$ near the middle with one elongate and one short ad. - Abdomen with light yellowish grey dusting, with dark pattern. $1+2^{\text {nd }}$ tergite entirely brownish black, $3^{\text {rd }}$ tergite in hind 0.3 with brownish grey stripe, which formed middle triangle shining black area; $4^{\text {th }}$ tergite in hind 04 with black pattern, consisted from median spot and lateral stripes, separated by narrow pollinose areas; $5^{\text {th }}$ tergite in hind 0.6 with oval median spot and paired rectangle lateral spots in hind 0.4 .

Male. Unknown.

Etymology: The species epithet is an adjective formed from the Latin word moderabilis - moderate.

Distribution: Palaearctic: Asia: Israel.

Xeromyia nahalica Verves et Khrokalo, sp. n.

Material. Type. Holotype: ơ, Israel: Nahal Lavan, 30.04.1996, leg. I. Yarom. Deposited in TAU.

Differential diagnosis: Similar to X. merei (Séguy, 1941) in the presence of 2 pairs of proclinate orb and frontal vitta narrower than parafrontalia, but distinctly differing by the presence of several black setae in fore part of gena.

Male. Body length $4.0 \mathrm{~mm}$. - Head yellowish white pollinose, frontal vitta yellow, slightly pollinose, vertex fuscous, antenna and palp yellow, apex of arista blackish. Frons at vertex $0.39 \times$, at level of antennal base $0.38 \times$ head-width. Frontal vitta $2.3 \times$ widened backwards, in the middle of frons $0.7 \times$ as wide as one of parafrontalia. Postpedicel $4.2 \times$ as long as pedicel, arista widened in basal 0.8. Parafacialia at level of antennal base $0.20 \times$, gena $0.06 \times$ eye-height. Palp long, at apex strongly widened. oc medium long; fr 11-12, long and strong; orb 1+2, all pairs long and strong; parafrontalia and parafacialia with microscopic light setae; gena with more long yellowish white setae, in fore part with several black setae; $v i$ one pair; oral setae absent. - Thorax dark, light grey pollinose, longitudinal stripes of mesonotum absent, apex of scutellum yellowish, covered with medium long black setae. acr $0+1 ; d c 0+1-2 ;$ ia $1+1-2 ;$ pprn 2; npl 2 (without setulae). Scutellum with 3 pairs of long marg and one pair of more short $d s$. - Wings hyaline. Costal spine absent, petiolus of cell $r_{4+5} 0.5 \mathrm{x}$ as long as $r-m, R_{4+5}$ bare, $M$-vein right-angled, $d m$-cu arched. $t_{2}$ with one $a d$. Legs black, all $f$ yellow at apex, $t_{1}$ and $t_{3}$ yellow in basal $1 / 3-1 / 2, t_{2}$ entirely yellow, all tarsi brownish black. Abdomen in greater part intensively light grey pollinose; $1+2^{\text {nd }}$ tergite dorsally with unclear brown middle spot and lateral spots in hind part; each of $3^{\text {rd }}$ and $4^{\text {th }}$ tergites in hind 0.4 with median spot and paired lateral stripes, divided by distinct pollinose areas, which only slightly narrower than median spot; $5^{\text {th }}$ tergite in hind $2 / 3$ with 3 black spots.

Female. Unknown.

Etymology: The species epithet is formed from the first word of the full name of the type locality, Nahal.

Distribution: Palaearctic: Asia: Israel.

\section{Xeromyia omanica Verves et Khrokalo, sp. n.}

Material. Type. Holotype: o; Oman: Wadi Quryat Ag. Stn. 500 m, 5.03.1976, leg. K. Guichard. Deposited in NHMUK.

Differential diagnosis: Similar to X. africana (Rohdendorf, 1930) in the abdominal pattern, well differing by very broad frons and more dark coloration of abdomen.

Female. Body length $4.0 \mathrm{~mm}$. - Head yellowish white pollinose, frontal vitta yellow, slightly pollinose, vertex fuscous, antenna and palp yellow, apex of arista blackish. Frons at vertex $0.46 \times$, at level of antennal base $0.38 \times$ head-width. Frontal vitta $2.5 \times$ widened 
backwards, in the middle of frons $1.7 \times$ as wide as one of parafrontalia. Postpedicel $3.7 \times$ as long as pedicel, arista widened in basal 0.9. Parafacialia at level of antennal base $0.16 \times$, gena $0.07 \times$ eye-height. Palp long, at apex strongly widened. oc medium long; fr 6-7, long and strong; orb 1+1, both pairs long and strong; parafrontalia and parafacialia with microscopic light setae; gena with more long yellowish white setae; vi one pair; oral setae absent. - Thorax covered with medium long black setae, dark grey pollinose with golden ting, longitudinal stripes of mesonotum linear, apex of scutellum brownish. acr $0+1 ; d c 0+1-2 ;$ ia $1+1-2$; pprn 2; $n p l 2$ (without setulae). Scutellum with 3 pairs of long marg and one pair of more short ds. - Wings hyaline. Costal spine absent, cell $r_{4+5}$ petiolate, $R_{4+5}$ bare, $M$-vein right-angled, $d m$-cu s-like curved. - Legs black, all $f$ yellow at apex, $t_{1}$ and $t_{3}$ yellow in basal $1 / 3-1 / 2, t_{2}$ entirely yellow, fore and mid tarsi yellowish brown, hind tarsi brownish black. $t_{2}$ with one $a d$. - Abdomen in greater part black, very fine golden pollinose, mat. $1+2^{\text {nd }}$ and $3^{\text {rd }}$ tergites yellow laterally; $1+2^{\text {nd }}$ tergite almost entirely black dorsally; $3^{\text {rd }}$ tergite in hind 0.4 with median spot and paired lateral stripes, which divided by very narrow pollinose areas; $4^{\text {th }}$ tergite with similar pattern, but pollinose areas between spot and stripes somewhat broader; $5^{\text {th }}$ tergite with 3 spots, median spot placed in hind 0.6 , lateral spots - in hind 0.5 of this tergite.

Male. Unknown.

Etymology: The species epithet is formed from the name of the state Oman.

Distribution: Palaearctic: Asia: Oman.
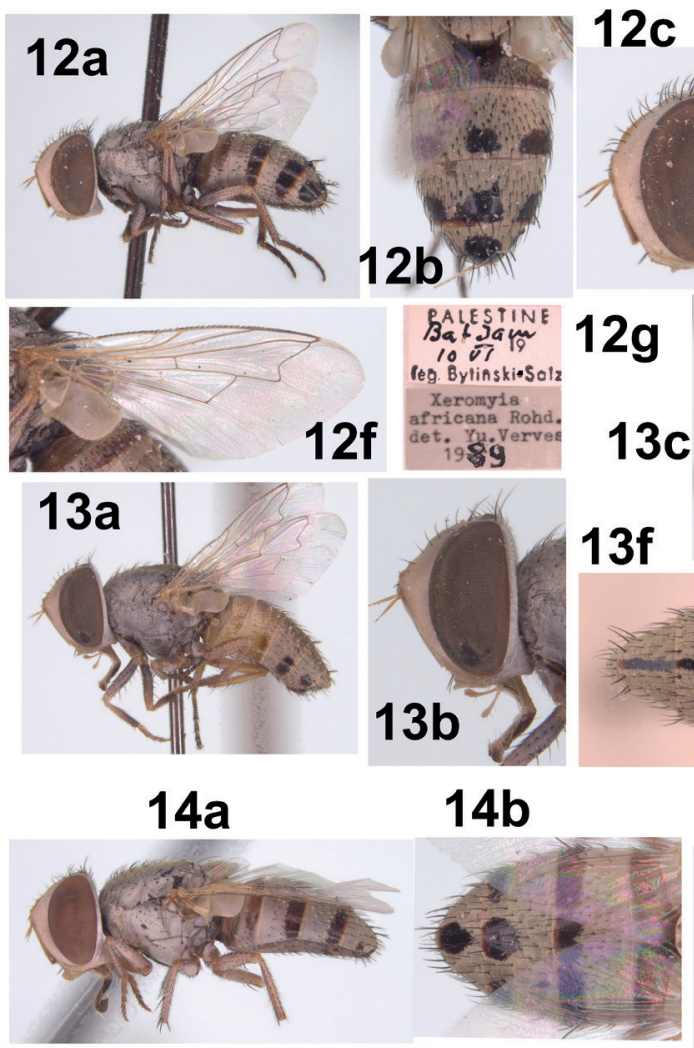

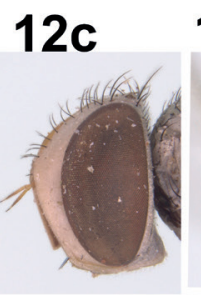

$12 d$
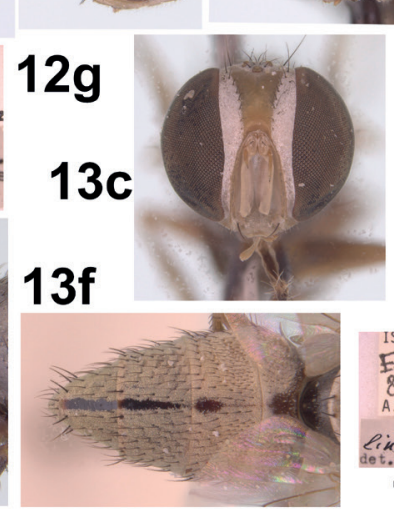

$14 \mathrm{c} 14 \mathrm{~d}$
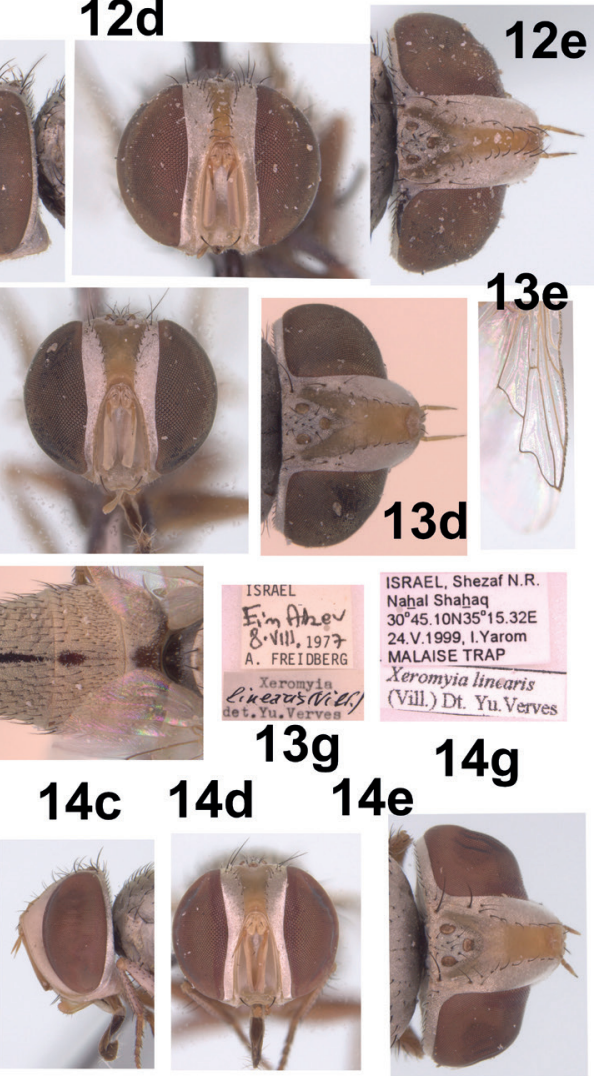

ISRAEL, Shezaf N.R. Nahal Shahaq
$30^{\circ} 45.10 \mathrm{~N} 35^{\circ} 15.32 \mathrm{E}$ 24.V.1999, I.Yarom MALAISE TRAP

Xeromyia linearis (Viil.) Dt. Yu. Verves

$14 \mathrm{~g}$

Fig. 12. Xeromyia africana (Rohd.) (female): a - habitus in lateral view; b - abdomen in dorsal view; $\mathrm{c}$-head in profile; $\mathrm{d}$-head in frontal view; $\mathrm{e}$ - head in dorsal view; $\mathrm{f}$ - wing; $\mathrm{g}$ - label.

Figs 13-14. Xeromyia orthogona (Rohd.). 13 (male): a - habitus in lateral view; b - head in profile; c - head in frontal view; $\mathrm{d}$ - head in dorsal view; e - wing; $\mathrm{f}$ - abdomen in dorsal view; $\mathrm{g}$ - label. 14 (female): a habitus in lateral view; $\mathrm{b}-$ abdomen in dorsal view; $\mathrm{c}$ - head in profile; $\mathrm{d}$-head in frontal view; $\mathrm{e}$ - head in dorsal view; $g$ - label. 
Xeromyia orthogona (Rohdendorf, 1925) (figs 13-14)

Apodacra (Xeromyia) orthogona Rohdendorf, 1925 a: 72; 1930: 17 (redesripion).

Xeromyia orthogona: Koçak \& Kemal, 2015: 352 (faunistic); Rohdendorf \& Verves, 1980: 495 (redescription of o', faunistic); Verves, 1986: 86 (catalog); Verves et al., 2015: 271 (review).

Apodacra (Xeromyia) oxygona Rohdendorf, 1925 a: 72.

Apodacra (Xeromyia) oxygona: Rohdendorf, 1930: 17 (redesription).

Apodacra oxygona: Ozerov \& Krivosheina, 2016: 814 (holotype revised).

Apodacra linearis Villeneuve, 1933: 255.

Apodacra linearis: Séguy 1941: 252 (in key), 255 (redescription).

Xeromyia linearis: Rohdendorf \& Verves, 1980: 496 (in key); Verves, 1986: 86 (catalog).

Apodacra (Xeromyia) aegyptiaca Rohdendorf, 1934: 9.

Material. Israel: 1 ơ, 1 , Hameshar, 16.06.1986, leg. A. Freidberg (TAU). 1 ○, Nahr Rubin, 1.09.1954, leg. O. Theodor (TAU). 1 o, Be’er Meshash, 16.06.1986, leg. A. Freidberg (TAU). 1 ○’, Ein Bogeg, 29.09.1971, leg. A. Freidberg (TAU). 1 \%, Sedom, 13.08. 1958, leg. J. Krykepst (TAU). 1 o, Ein Aqev, 8.08. 1977, leg. A. Freidberg (TAU). $10^{\circ,} 2$ o, Shezaf N. R., Nahal Shahaq, 24 and 31.05.1999, leg. I. Yarom (TAU). 4 o, Hazeva Field

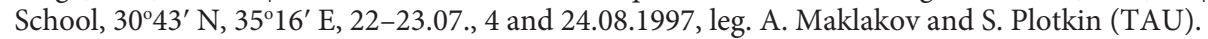

Distribution: Palaearctic: North Africa: Egypt; Asia: Israel, Kazakhstan, Turkmenistan, Uzbekistan, Mongolia.

Habits: Adult flies prefer sandy and stone areas.

Xeromyia merei (Séguy, 1941) (figs 15-16)

Apodacra merei Séguy, 1941: 255.

Xeromyia merei: Rohdendorf \& Verves, 1980: 496 (in key); Verves, 1986: 86 (catalog); Verves et al., 2015: 271 (review). $(\mathrm{PCV})$.

Material. Israel: 3 ơ, 2 , Negev, dunes along Nahal Sekker, n. Ramat Khoval, 13.05.2006, K. Szpila

Distribution: Palaearctic: Asia: Israel; North Africa: Algeria, Mauritania.

Xeromyia ponti Verves et Khrokalo, sp. n.

Material. Type. Holotype: ơ: Saudi Arabia: Kushm Dibl, 19.05.1978, leg. W. Buttiker. Deposited in NHMUK. Paratype: o: same data as holotype. Deposited in NHMUK.

Differential diagnosis: Similar to X. orthogona (Rohdendorf, 1925) in the abdominal pattern and presence of black setae on gena, distinctly differing by the poorly differentiated, almost lacking lateral spots of $3^{\text {rd }}$ and $4^{\text {th }}$ abdominal tergites.

Body leng th 5.0-5.5 mm. Male. - Head yellow pollinose, frontal vitta yellow, slightly pollinose, vertex darker, antenna and palp yellow, apex of arista blackish. Frons at vertex $0.43 \times$, at level of antennal base $0.33 \times$ head-width. Frontal vitta $2.2 \times$ widened backwards, in the middle of frons $2.0 \times$ as wide as one of parafrontalia. Postpedicel $0.5 \times$ as long as pedicel, arista widened almost to apex. Parafacialia at level of antennal base $0.17 \times$, gena $0.08 \times$ eyeheight. Palp long, at apex strongly widened. oc long and strong; fr 9-10, medium long; orb $1+1$, strong; parafrontalia and parafacialia with microscopic light setae; gena covered with black setae, in hind parts with mixed yellow and black setae; instead of $v i$, other oral setae absent. - Thorax covered with black medium long setae, densely grey pollinose, medial longitudinal stripes of tergites linear, apex of scutellum yellowish brown. acr $0+1, d c 0+1$; ia 1+1; pprn 2; $n$ pl 2 (without setulae). Scutellum with 3 pairs of strong marg and one pair of crossed $d s$. - Wings are not preserved. - Legs almost entirely yellow, only middle part of fore femora grey pollinose. $t_{2}$ with one $a d$. - Abdomen densely light orange yellow pollinose, with very narrow black longitudinal median line on $1+2^{\text {nd }}-5^{\text {th }}$ tergites. $5^{\text {th }}$ tergite in hind $1 / 3$ with a pair of lateral small rounded shining brownish black spots, $3^{\text {rd }}$ and $4^{\text {th }}$ tergites with remains of similar spots. Terminalia small, brownish yellow, light pollinose.

Female. - Head. Frons at vertex $0.38 \times$, at level of antennal base $0.28 \times$ head-width; genal black setae distinctly smaller than in $0^{*}$. - Wings hyaline. Costal spine absent, cell $r_{4+5}$ 

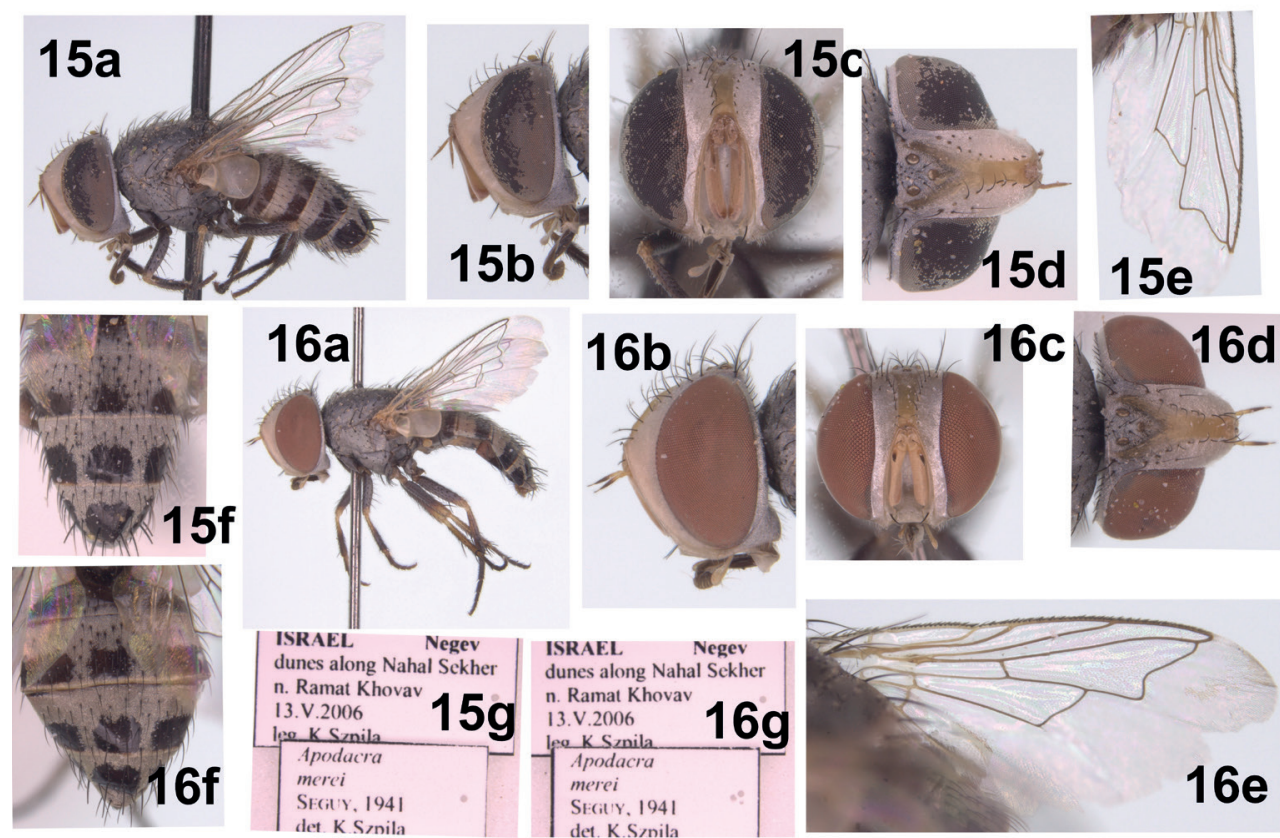

Figs 15-16. Xeromyia merei (Séguy. 15 (male): a - habitus in lateral view; b - head in profile; $c-$ head in frontal view; $\mathrm{d}$ - head in dorsal view; e - wing; $\mathrm{f}$ - abdomen in dorsal view; $\mathrm{g}$ - label. 16 (female): a habitus in lateral view; $\mathrm{b}$ - head in profile; $\mathrm{c}$ - head in frontal view; $\mathrm{d}$ - head in dorsal view; $\mathrm{e}-$ wing; $\mathrm{f}-$ abdomen in dorsal view; $\mathrm{g}-$ label.

petiolate, $M$-vein acute-angled, $R_{4+5}$ bare, $d m$-cu s-like curved. - Legs yellow, only hind tarsi and apex of hind tibia fuscous. - Abdomen orange yellow, slightly light pollinose. $4^{\text {th }}$ tergite in hind 0.5 with rounded dark brown median spot, $5^{\text {th }}$ tergite with similar spot in hind $2 / 3$ and with the remains of yellowish lateral stripes.

Etymology: The species is named in honor of the well known British entomologist, Mr Adrian C. Pont (Oxford University Museum of Natural History).

Distribution: Palaearctic: Asia: Israel.

\section{Xeromyia stenorhina (Rohdendorf, 1934) (figs 17-18)}

Apodacra (Xeromyia) stenorhina Rohdendorf, 1934: 8.

Xeromyia stenorhina: Koçak \& Kemal, 2015: 352 (faunistic); Rohdendorf \& Verves, 1980: 497 (in key); Verves, 1986: 86 (catalog); Verves \& Khrokalo, 2018 (Supplementary Material): 21 (faunistic); Verves et al., 2015: 272 (review).

Material. Israel: 1 , , Yeriho, 16.11.1972, leg. M. Kaplan (TAU). 1 o, ’En Gedi, 30.03.1919, leg. BytinskiSalz (TAU). 2 O', Sede Boqer, 1.05.1954 and 7.09.1972, O. Theodor and M. Kaplan (TAU). 4 O', Ein Aqev, 8.08.1972, leg. A. Freidberg (TAU). 1 đ', Ein Rhadian, Dunes, Sth Palestine, without data, leg. O. Theodor. 1 \&, Ras Fehkha, 22.11.1976, leg. M. Kaplan (TAU).

Distribution: Palaearctic: North Africa: Egypt; Asia: Israel.

Habits: Psammophilous and xerophilous species.

\section{Xeromyia sulcata (Villeneuve, 1933)}

Apodacra sulcata Villeneuve, 1933: 255.

Xeromyia sulcata: Verves, 1986: 86 (catalog); Verves \& Khrokalo, 2018 (Supplementary Material): 21 (faunistic); Verves et al., 2015: 272 (review).

Material. 1 \&, Ne'ot Semadar, 13.10.1996, leg. A. Freidberg (TAU).

Distribution: Palaearctic: North Africa: Egypt; Asia: Israel.

Habits: Psammophilous and xerophilous species. 

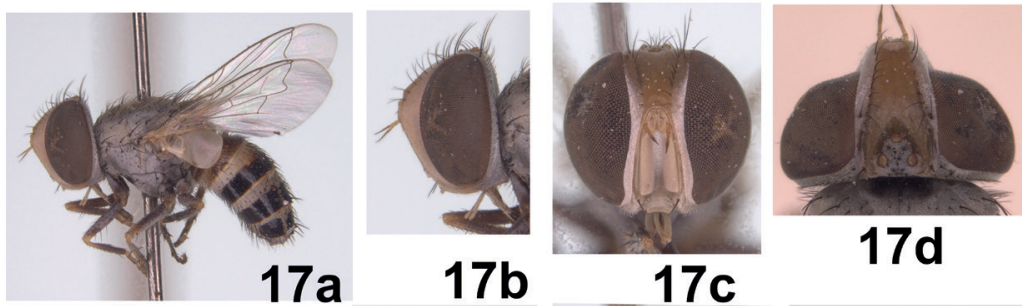

$17 d$
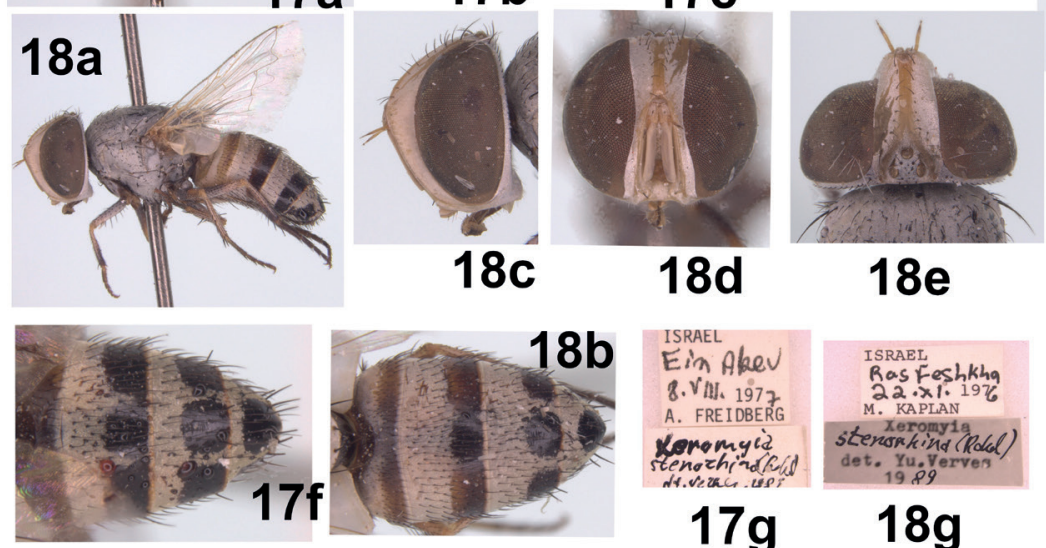

$18 \mathrm{e}$

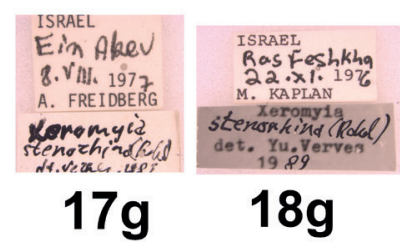

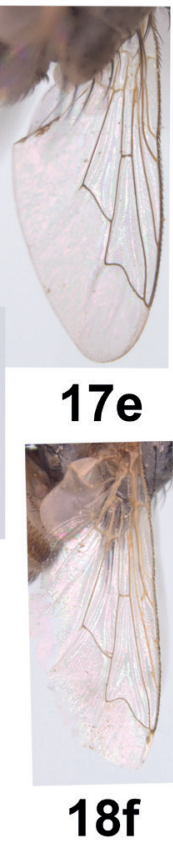

Figs 17-18. Xeromyia stenorhina (Rohd.). 17 (male): a — habitus in lateral view; b - head in profile; c - head in frontal view; $\mathrm{d}$ - head in dorsal view; e — wing; $\mathrm{f}$ - abdomen in dorsal view; $\mathrm{g}$ - label. 18 (female): a habitus in lateral view; $\mathrm{b}$ - abdomen in dorsal view; $\mathrm{c}$ - head in profile; $\mathrm{d}$ - head in frontal view; $\mathrm{e}-$ head in dorsal view; f - wing; g - label.

\section{Genus Xerophilomyia Rohdendorf, 1925}

Xerophilomyia Rohdendorf, 1925: 64 (as subgenus of Apodacra Macquart, 1854). Type species: Apodacra leucocera Rohdendorf, 1925, by designation of Townsend, 1938: 152.

Xerophilomyia: Rohdendorf, 1930: 12, as a subgenus of Apodacra Macquart, 1854 (revision); Rohdendorf \& Verves, 1980: 491 (key to species); Verves, 1986: 86 (catalog); 1990: 540 (key to East Palaearctic species); Verves et al., 2015: 273 (review).

Diagnisis. Medium sized $(5.5-10.0 \mathrm{~mm})$ bright colored flies. Frons and face as wide as one eye; vibrissal angles distinctly raised over oral margin, and lunula narrowed downwards; head in profile angular; hind border of head distinctly shortened; proclinate orb numerous, as a group of irregular placed erect setae; Postpedicel 2.0-2.5 $\times$ as long as pedicel. $\sigma^{\top}: f_{2}$ and $t_{2}$ with ctenidium consisting of long and flattened setae.

Twenty species occur in the south of the Palaearctic and Afrotropical Regions.

\section{Key to species}

1.

$-$

2. $f_{2}$ with ctenidium composed of flattened dorsal setae; dorsal and ventral ctenidiums of $t$, placed in apical 0.4-0.5; mid $1^{\text {st }}$ tarsomere widened (fig. 20, e). Middle spot of $3^{\text {rd }}$ abdominal tergite separated from lateral ones by broad stripes of dusting; pattern of abdomen black (fig. 20, g). Mid tarsus partly or entirely orange yellow. $4.5-8.0 \mathrm{~mm}$.

X. nigropicta Rohdendorf, 1934

- $\quad f_{2}$ without ctenidium; dorsal ctenidium of $t_{2}$ placed in apical $0.2-0.3$ only; mid $1^{\text {st }}$ tarsomere not widened. Middle spot of $3^{\text {rd }}$ tergite more or less united with lateral stripes; lateral stripes of abdomen usually reddish (fig. 22, g).

3. Mid tarsus entirely orange yellow; parafrontal setose in posterior half only (fig. 22, b-d). Fore $4^{\text {th }}$ tarsomere without specialised setae; $t_{2}$ with flattened setae in distal 0.3-0.5 (fig. 22, e). 6.5-9.5 mm.

X. plumipes (Villeneuve, 1933)

- Mid tarsus distinctly blackish; parafrontalia setose almost to lunula, setosity gradually fading out and ending just before reaching the level of the anteriormost frontal seta. $4^{\text {th }}$ tarsomere of fore tarsus with a 
long, straight, stronger $p$ and an almost equally long but more curved, slender $a$ (see fig. 1 in Pape, 1988); $t_{2}$ with flattened setae along most of its length. 5.0-8.0 $\mathrm{mm}$. X. cyprica (Rondani, 1859)

4. Mid tarsus distinctly blackish. ... 5

- $\quad$ Mid tarsus partly or entirely orange yellow.

5. $\quad 3^{\text {rd }}$ abdominal tergite with entire black hind stripe. $X$ cyprica (Rondani, 1859)

6. $\quad 3^{\text {rd }}$ abdominal tergite with rounded middle spot and paired lateral stripes in hind 0.4 .................................
orb reach to level of fore $f r$; frontal vitta golden pollinose in hind part only (figs $19, \mathrm{~b}-\mathrm{d}$ ); abdomen yel lowish grey pollinose, with lateral yellow areas (figs 19, a, e, f). $6.0 \mathrm{~mm}$ X. nigritarsus sp. $\mathbf{n}$. orb reach to mid length of frons; frontal vitta entirely silver pollinose; abdomen light grey pollinose, without lateral yellow areas. $5.7 \mathrm{~mm}$. $X$. famagustica Verves et Khrokalo, sp. n.

7. Middle spot of $3^{\text {rd }}$ abdominal tergite separated from lateral stripes by broad pollinose areas (fig. 21, b). X. nigropicta Rohdendorf, 1934

- $\quad 3^{\text {rd }}$ abdominal tergite with entire black or laterally yellowish-red hind stripe (figs $\left.23, a, b, f\right)$..... X. plumipes (Villeneuve, 1933)

\section{Xerophilomyia cyprica (Rondani, 1859)}

Apodacra cyprica Rondani, 1859: 221; Pape, 1988: 7 (type revised); Pape \& Blasco-Zumeta, 1997: 93 (habits); Pape et al., 2002: 218 (faunistics); Séguy, 1941: 252 (in key), 255 (redescription); Szpila, 2010: 22 (morphology of $1^{\text {st }}$ instar larva); Venturi, 1957b: 154 (redescription).

Apodacra (Xerophilomyia) cyprica: Rohdendorf, 1930: 14 (diagnose).

Xerophilomyia cyprica: Koçak \& Kemal, 2012: 954, 1008, 1054, 1096, 1173, 1198, 1253; 2015: 352 (faunistics); Rohdendorf \& Verves, 1980: 461 (in key); Verves, 1986: 87 (catalog); Verves \& Khrokalo, 2018 (Supplementary Material): 21 (faunistics); Verves et al., 2015: 273 (review).

Apodacra bembicisequax Pandellé, 1895: 288; Pape, 2004: 18 (lectotype designated); Séguy, 1941: 253 (in key), 255 (type revised).

Apodacra (Xerophilomyia) bembicisequax: Rohdendorf, 1930: 13 (diagnose).

Material. Israel: 1 ○, Lahav, 19.07.1971, leg. A. Freidberg (TAU). 4 ơ, 1 \&, N. Zafit, pupae 23.03.1977 ex Eumenes nest, imagoes 15.04.1971, leg. J. Kugler (TAU). 1 o, Arava Walley, 2 km N of Hazeva Field School in Wadi

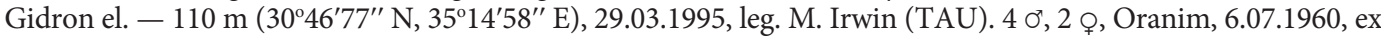
nest of Eumenes (Delta) asinus, leg. Abalafia (NHMUK). 4 , , Hazeva, 27.09.1979, ex pupae Rhynchium sp. (TAU).

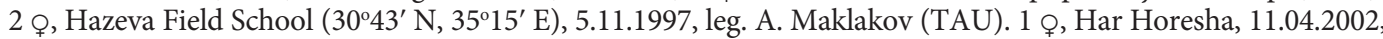
leg. A. Freidberg (TAU). 5 ơ, 1 \&, Elat, 30.06.1975, leg. A. Lapo (TAU). Egypt: 1 ơ, Sinai, Ein Fortaga, 12.08.1971, leg. J. Kugler (TAU). 3 o, Sinai, Sarabit el-Chadem, 12.09.1975, coccon of Eumenes sp., 17.10.1975, ex coccon, leg. D. Aizikovitch (TAU). Jordan*: 1 ơ, Jordan Valley, Zerda R. Valley, c. 200 m, at light, 18.09.1954 (NHMUK).

Distribution: Palaearctic: Europe: Spain, France (south part and Corsica); North Africa: Egypt (mainland); Asia: Cyprus, Egypt (Sinai), Israel, Jordan*.

Habits: Psammophilous and xerophilous species. Larvae are kleptoparasites in nests of eumenid wasps: Delta asinus (Sauss.), Eumenes sp., Euodynerus variegatus (F.), Rhynchium sp. and sphecid wasps: Bembex sp.

\section{Xerophilomyia famagustica Verves et Khrokalo, sp. n.}

Material. Type. Holotype: o, Cyprus: Famagusta, 21.05.1948. Deposited in NHMUK.

Differential diagnosis: Similar to X. nigritarsus sp. n. in the black mid tarsus and abdominal pattern, differing by the following characters: orb reach to mid length of frons; frontal vitta entirely silver pollinose; abdomen light grey pollinose, without lateral yellow areas.

Female. Body length $5.7 \mathrm{~mm}$. - Head. Parafrontalia and parafacialia yellowish white pollinose, more dark at vertex, lunula and gena silvery white pollinose, frontal vitta yellow, entirely silver pollinose, antenna and palp yellow, apical part of arista fuscous, occiput light grey pollinose. Frons at vertex $0.36 \times$, at level of antennal base $0.30 \times$ headwidth. Frontal vitta $1.6 \times$ widened backwards, at level of middle of frons length $2.0 \times$ as wide as one of parafrontalia. Postpedicel $2.4 \times$ as long as pedicel, arista widened in basal 0.4 Parafacialia at level of antennal base $0.16 \times$, gena $0.07 \times$ eye-height. Palp medium long, at apex widened. oc fine; fr 12-13, strong, in fore part of frons crossed; orb 20-25, very short, 
seta-like, reach to mid length of frons; parafrontalia with microscopic light setae; gena with more long yellow setae; 2 pairs of vi. - Thorax covered with medium long black setae, densely grey pollinose, longitudinal stripes absent, scutellum yellowish brown at apex, pleurae light grey pollinose. acr $0+1, d c 3+3-4$, only prescutellar one straight; ia $1+1$; pprn 2; npl 2 (without setulae). Scutellum with 3 pairs of long marg; $d s$ badly developed. - Wings hyaline. Costal spine absent, petiolus of cell $r_{4+5}$ short, $0.3 \times \mathrm{x}$ as long as $r-m$; $R_{4+5}$ bare, $M$-vein acute-angled, $d m$-cu straight. - Legs yellow, $f_{1}$ and $f_{3}$ almost entirely, $f_{2}$ in basal part light grey pollinose; all tibia yellow, $t$ light grey pollinose, all tarsi black; $t_{2}$ with 2 $a d$. - Abdomen light grey pollinose, without lateral yellow areas. $3^{\text {rd }}$ tergite with rounded middle spot and paired lateral stripes in hind 0.4, the distance between spot and stripes relatively equal to diameter of middle spot; $4^{\text {th }}$ tergite with similar pattern, but distance between stripes and spot less than diameter of middle spot; $5^{\text {th }}$ tergite in hind $2 / 3$ with 3 distinctly spots. All spots and stripes black. $1+2^{\text {nd }}$ and $3^{\text {rd }}$ abdominal tergites without medio-marginals.

Male. Unknown.

Etymology: The species epithet is formed from the name of the type locality, Famagusta.

Distribution: Palaearctic: Europe: Cyprus.

Xerophilomyia nigritarsus Verves et Khrokalo, sp. n. (fig. 19)

Material. Type. Holotype: o, Israel: Lahave, 27.03.1972, leg. J. Kugler. Deposited in TAU.

Differential diagnosis: Xerophilomyia nigritarsus sp. $\mathrm{n}$. is similar to X. ctenoscelis (Rohdendorf, 1925) from Central Asia in the abdominal pattern, differing by the black tarsi of all legs.

Female. Body length 5.5-6,0 mm. - Head. Parafrontalia and parafacialia yellowish grey pollinose, darker at vertex, lunula and gena silvery white pollinose, frontal vitta yellow, in fore part shine, in hind part fine golden pollinose, antenna and palp yellow, apical part of arista fuscous, occiput light grey pollinose. Frons at vertex $0.38 \times$, at level of antennal base $0.34 \times$ head-width. Frontal vitta $1.5 \times$ widened backwards, at level of middle of frons length $1.3 \times$ as wide as one of parafrontalia. Postpedicel $2.0 \times$ as long as pedicel, arista widened in basal 0.4 . Parafacialia at level of antennal base $0.16 \times$, gena $0.07 \times$ eyeheight. Palp medium long, at apex widened. Oc fine; fr 12-13, strong, in fore part of frons crossed; orb 14-18, seta-like, reach to level of fore $f r$; parafrontalia with microscopic light setae; gena with more long yellow setae; 2 pairs of vi. - Thorax covered with medium long black setae, densely grey pollinose, longitudinal stripes absent, scutellum yellowish brown at apex, pleurae light grey pollinose. acr 1+1-2, dc 2+3-4; ia 1+1; pprn 2; npl 2 (without setulae). Scutellum with 3 pairs of long marg ( $a p$ crossed) and one pair of shorter $d s . t_{2}$ with one $a d$. - Wing hyaline. Costal spine absent, petiolus of cell $r_{4+5}$ short, $0.3 \times$ as long as $r-m ; R_{4+5}$ bare, $M$-vein acute-angled, $d m$ - $c u$ almost straight. - Legs yellow, $f_{1}$ and $f_{3}$ almost entirely, $f_{2}$ in basal part light grey pollinose; all tibia yellow, $t_{1}$ slightly fuscous, all tarsi black. - Abdomen yellowish grey pollinose, tergites with dorsal black spots and stripes and lateral yellow areas. $3^{\text {rd }}$ tergite with rounded middle spot and paired lateral stripes in hind 0.4 , the distance between spot and stripes more than diameter of middle spot; $4^{\text {th }}$ tergite with similar pattern, but distance between stripes and spot less than diameter of middle spot; $5^{\text {th }}$ tergite in hind $2 / 3$ with 3 connected spots. $1+2^{\text {nd }}$ and $3^{\text {rd }}$ abdominal tergites without medio-marginals.

Male. Unknown.

Etymology: The species epithet is a noun in apposition formed from the Latin words niger - black, dark, and tarsus.

Distribution: Palaearctic: Asia: Israel. 


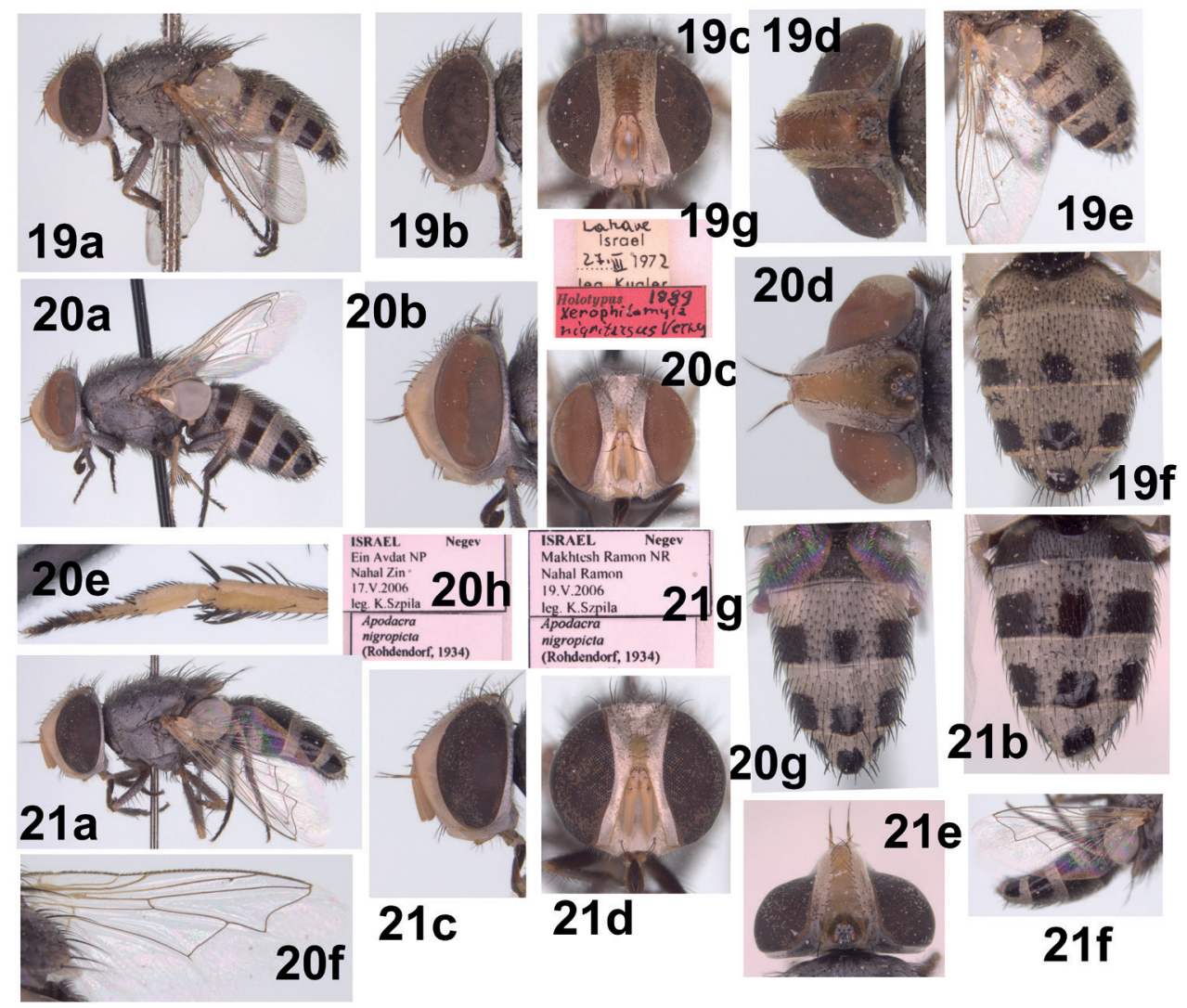

Fig. 19. Xerophilomyia nigritarsus sp. $\mathrm{n} . \mathrm{a}$ - habitus in lateral view; $\mathrm{b}$ - head in profile; $\mathrm{c}$ - head in frontal view; $\mathrm{d}$-head in dorsal view; $\mathrm{e}$ - wing \& abdomen in dorsolateral view; $\mathrm{f}$ - abdomen in dorsal view; $\mathrm{g}$ - label. Figs 20-21. Xerophilomyia nigropicta Rohd. 20 (male): a - habitus in lateral view; b - head in profile; c - head in frontal view; $\mathrm{d}$ - head in dorsal view; e - widdle leg in antrerior view; $\mathrm{f}$ - wing; $\mathrm{g}$ - abdomen in dorsal view; $\mathrm{h}$ - label. 21 (female): a - habitus in lateral view; $\mathrm{b}$ - abdomen in dorsal view; $\mathrm{c}$ - head in profile; $\mathrm{d}$ head in frontal view; $\mathrm{e}$ - head in dorsal view; $\mathrm{f}$ - wing abdomen, lateral view; $\mathrm{g}$ - label.

\section{Xerophilomyia nigropicta Rohdendorf, 1934 (figs 20-21)}

Xerophilomyia nigropicta Rohdendorf, 1934: 6; Koçak \& Kemal, 2015: 352 (faunistic); Rohdendorf \& Verves, 1980: 461 (in key); Verves, 1986: 87 (catalog); Verves \& Khrokalo, 2018 (Supplementary Material): 21 (faunistic); Verves et al., 2015: 274 (review).

Apodacra nigropicta: Mazen \& Aal, 2007: 11 (habits); Piwczyński et al., 2017: 53, 57 (in dendrograms); Szpila \& Pape, 2016: 96 (morphology of $1^{\text {st }}$ instar larva).

Material. Israel: 1 đ', Yeriho, 27.04. 1973, leg. A. Freidberg (TAU). 2 ơ, 7 ○, Be’er Meshash, 20.04. 1978, ex nest of Eumenidae in stem, leg. M. Kaplan (TAU). 1 đ', Qumran, 24.03. 1986, leg. F. Kaplan (TAU). 1 ơ, Ein Gedi, 16.12. 1972, leg. M. Kaplan (TAU). 1 ơ, Arad, 21.04. 1981, leg. F. Kaplan (TAU). 1 ơ, Nahal Uvda, Shaharut Junc. 2.05. 1986, leg. A. Freidberg (TAU). 1 \&, Avdat, 19.04. 1975, leg. A. Freidberg (TAU). 1 O', Bir Rekhme, 27. 03. 1958, ex Eumenidae, leg. L. Fishelsohn (TAU). 1 o, Hazeva Field School, 24. 02. 1998, leg. S. Plotkin (TAU). 1 ơ, Ein Feshkha, 26. 02. 1974, leg. M. Kaplan (TAU).

Morphological notes: ơ: 1-3 pairs of strong vi; $f_{2}$ with ctenidium consisted from long and widened $a ; t_{2}$ with ctenidium at upper and lower surfaces in apical half; 1 st tarsomere of fore tarsi very widened.

Distribution: Palaearctic: North Africa: Egypt (mainland); Asia: Israel.

Habits: Larvae have been recorded from nests of eumenid wasps. 
Xerophilomyia plumipes (Villeneuve, 1933) (figs 22-23)

Apodacra plumipes Villeneuve, 1933: 254; Pape, 1988: 7 (discussion); 2004: 19 (in key); Piwczyński et al., 2017: 53, 57 (in dendrograms); Séguy, 1941: 256 (redescription); Szpila, 2010: 23 (morphology of $1^{\text {st }}$ instar larva); Venturi, 1960: 35 (in key), 36 (discussion).

Xerophilomyia plumipes: Koçak \& Kemal, 2015: 352 (faunistic); Rohdendorf \& Verves, 1980: 462 (in key); Verves, 1986: 87 (catalog); Verves \& Khrokalo, 2018 (Supplementary Material): 21 (faunistic); Verves et al., 2015: 274 (review).

Material. Israel: 4 ơ, 2 ○, Oranim $\left(32^{\circ} 42^{\prime} 33^{\prime \prime} \mathrm{N}, 35^{\circ} 06^{\prime} 19^{\prime \prime} \mathrm{E}\right), 6.07 .1960$, ex nest of Eumenes (Delta) asinus, leg. Abalafia (NHMUK). $10^{\prime}$, Makhtech Ramon NR, Nahal Ramon, 19.05.2004, leg. K. Szpila (PCV). 1 o, Lahav, 19.07.1971, leg. A. Freidberg (TAU). 4 ơ, 1 o, N. Zafit, 23.03.1977, ex Eumenes nest 15.04.1971, leg. J. Kugler (TAU). 4 \&, Hazeva, 27.09.1979, ex pupae Rhynchium sp. (TAU). 1 o', 1 o, Hazeva, Field School $\left(30^{\circ} 43^{\prime} \mathrm{N}, 35^{\circ} 15^{\prime} \mathrm{E}\right), 24.08$. \& 2.11.1997, S. Plotkin (TAU). $10^{\prime \prime}$, Zin Wilderness, Nahal Zin at An Akrabim canecovered sandy wadi el. - $61 \mathrm{~m}\left(30^{\circ} 53^{\prime} 38^{\prime \prime} \mathrm{N}, 35^{\circ} 09^{\prime} 39^{\prime \prime} \mathrm{E}\right), 10.04 .1995$, leg. M. Irwin (NHMUK). $50^{\prime \prime}, 1$ \&, Elat, 30.06.1975, leg. A. Lapo Egypt: 1 ơ, Sinai, Ein Fortaga, 12.08.1971, leg. J. Kugler (TAU). 2 o, Sinai, Sarabit elChadem, 12.04.1975, ex coccon of Eumenes, 17.10.1975, leg. D. Aizikovitch (TAU). Jordan*: 1 ơ, Jordan Valley, Zerda R. Valley, c. 200 m, at light, 18.09.1954 ( (NHMUK).

Distribution: Palaearctic: Europe: South France (mainland), Greece; North Africa: Morocco, Tunisia, Egypt; Asia: Egypt (Sinai), Israel, Jordan*, United Arab Emirates.

Habits: Larvae are kleptoparasites in pottery nests of eumenid wasps: Delta asinus (Sauss.), Eumenes sp., Rhynchium sp.

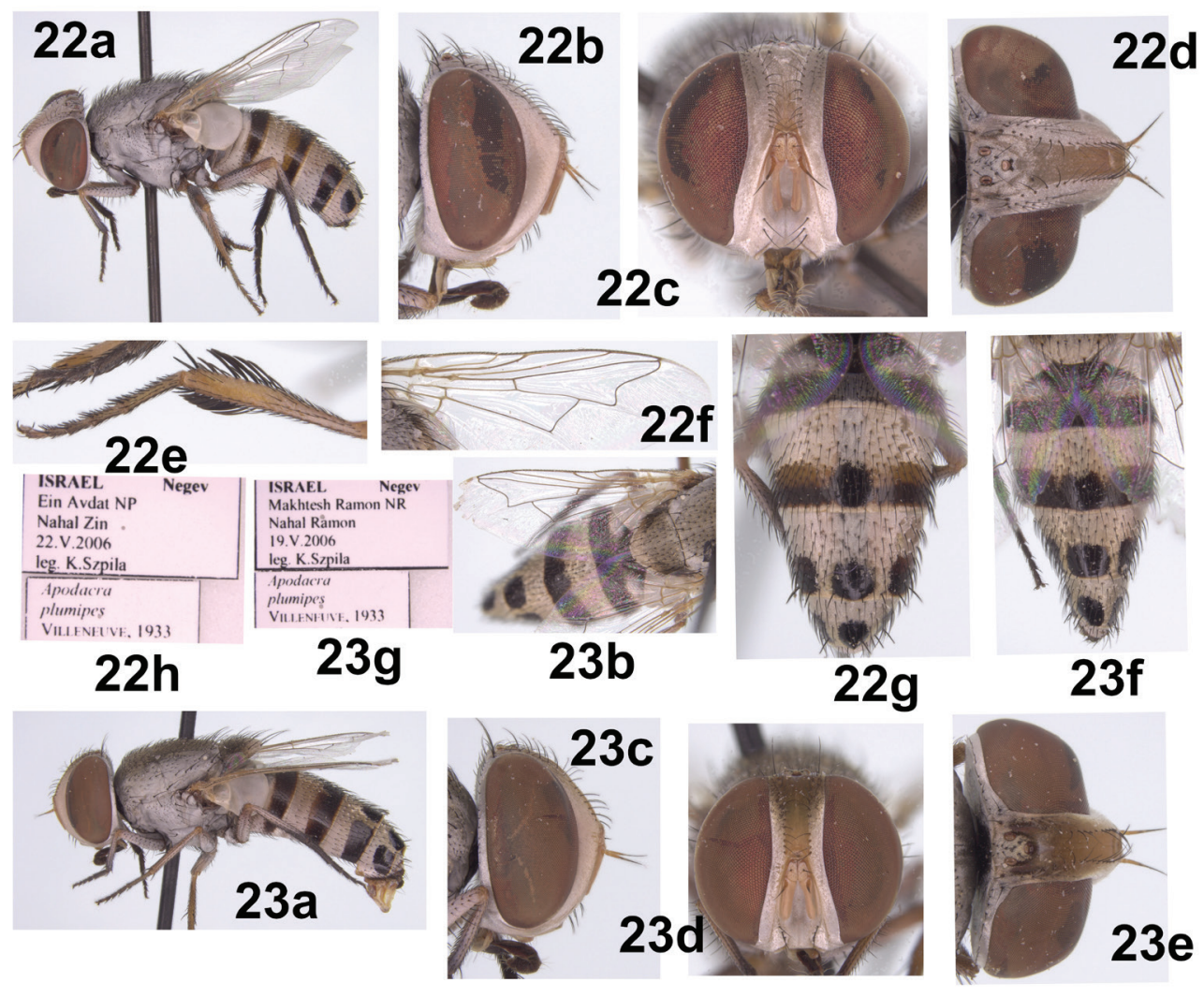

Figs 22-23. Xerophilomyia plumipes (Vill.). Fig. 22 (male): a - habitus in lateral view; b - head in profile; $\mathrm{c}$ - head in frontal view; $\mathrm{d}$ - head in dorsal view; $\mathrm{e}-$ middle leg in antrerior view; $\mathrm{f}-$ wing; $\mathrm{g}$ - abdomen in dorsal view; $\mathrm{h}$ - label. 23 (female): a - habitus in lateral view; b - wing \& abdomen in dorsolateral view; c head in profile; $\mathrm{d}$ - head in frontal view; $\mathrm{e}$ - head in dorsal view; $\mathrm{f}$ - wings \& abdomen, dorsal view; $\mathrm{g}$ - label. 


\section{Conclusion}

As the result of our studies, 27 species of Apodacrina from Middle East countries are listed. Among them ten new species are described: five from Israel (Apodacra idiopatica, A. melanura, Xeromyia moderabilis, X. nahalica, Xerophilomyia nigritarsus), two from Saudi Arabia (Xeromyia jeddaensis, X. ponti) and one by one from Cyprus (Xerophilomyia famagustica), Egypt (Apodacra firanensis), and Oman (Xeromyia omanica). Seventeen of them are recorded for Israel, ten for Egypt, four for Turkey, and three for Iran; only two species are known for each of Cyprus, Jordan, Saudi Arabia and United Arab Emirates, and one is known for Oman. No species have been recorded from Bahrain, Iraq, Kuwait, Lebanon, Qatar, Syria, and Yemen. Thus, the species composition of these insects in most of the study area is virtually unstudied. Comprehensive species lists exist only for Israel and Egypt.

We extend our warm thanks to Dr. A. Freidberg (TAU) and Mr. N. Wyatt (NHMUK) for making the material available to us. We are especially grateful to Prof. K. Szpila (Nicolaus Copernicus University, Toruń, Poland) for taking the high-quality photographs used in this work. We greatly appreciate a thorough reviewing of the manuscript with suggestions for valuable improvements by two anonymous referees and Dr. M. Kasparek (Heidelberg, Germany).

\section{References}

Egger, J. 1861. Dipterologische Beiträge. Fortzetzung der Beschreibung neuer Dipteren. Verhandlungen der (K. K.) Zoologish-Botanischen Gesellschaft in Wien, 11, 209-216.

Gorobchishin, V. A. 2006. Digger wasps (Hymenoptera: Sphecidae: Larrinae, Crabroninae, Mellininae, Nyssoninae, Philanthinae) of forest-steppes of Ukraine (fauna and ecology information). Proceedings of Zoological Museum of Kyiv Taras Shevchenko National University, 4, 105-154.

Grandi, G. 1961. Studi di un entomologo sugli imenotteri aculeati. XXXI. Bollettino del Laboratorio di Entomologia della Regio Istituto superiore d'Agricoltura in Bologna, 25, i-xvi, 1-659.

Holstein, J., Rudzinsky, H.-G. 1994. A remarkable record of Apodacra dispar Villeneuve (Diptera, Sarcophagidae, Miltogrammatinae) from southeast of Spain. Studia dipterologica, 1, 114-121.

Koçak, A. Ö., Kemal, M. 2015. Initial results of the entomofauna of SW Asia, based upon the info-system of the CESA (excl. Lepidoptera). Priamus, 35, 1-1186.

Macquart, J. P. M. 1854. Nouvelles observations sur les diptères de la tribu des tachinaires (Suite). Annales de la Société Entomologique de France (3e sér.), 2, 393-446.

Mazen, N. A. M., Aal, A. A. 2007. A study on some sarcophagid flies (Diptera), causing myiasis in Assiut, Egypt. Egyptian Journal of Experimental Biology (Zoology), 3, 9-18.

Merz, B., Haenni, J. P. 2000. Morphology and terminology of adult Diptera (other than terminalia). In: Papp, L. and Darvas, B., eds. Contributions to a manual of Palaearctic Diptera (with special reference to flies of economic importance). Science Herald Press, Budapest, 21-51.

Nandi, B. C. 2002. Diptera Sarcophagidae. Fauna of India and the adjacent Countries, 10, Zoological Survey of India, Calcutta, i-xxiv + 1-608.

Pape, T. 1988. A revision of the Palaearctic Sarcophagidae (Diptera) described by C. Rondani. Stuttgarter Beiträge zur Naturkunde, A (416), 1-22.

Pape, T. 2004. The Sarcophagidae (Insecta: Diptera) described by Louis Pandellé. Zootaxa, 722, 1-64.

Pape, T., Blasco-Zumeta, J. 1997. Apodacra cyprica Rondani (Diptera: Sarcophagidae) bred from Euodynerus variegatus (Fabricius) in Spain. Zapateri Revista Aragonesa de Entología, 6, 93-95.

Pape, T., González-Mora, D., Peris, S. V., Báez, M. 2002, Sarcophagidae. In: Carles-Tolrá Hjorth-Andersen, M., coordinator. Catálogo de los Diptera de España, Portugal y Andorra (Insecta). Monografías SEA, 8, 218-221.

Piwczyński, M., Pape, T., Deja-Sikora, E., Sikora, M., Akbarzadeh, K., Szpila, K. 2017. Molecular phylogeny of Miltogramminae (Diptera: Sarcophagidae): implications for classification, systematics and evolution of larval feeding strategies. Molecular Phylogenetics and Evolution, 116, 49-60.

Povolný, D., Verves, Yu. G. 1997. The flesh-flies of Central Europe (Insecta, Diptera, Sarcophagidae). Spixiana, Suppl. 24, 1-264.

Rohdendorf, B. B. 1925. Études sur les miltogrammines. II. Synopsis des apodacres palaeartiques. Encyclopédie Entomologique, B 2, 11 (1), 61-72.

Rohdendorf, B. B. 1927. Miltogramminen-Studien IV. Zoologischer Anzeiger, 71 (5-8), 157-169.

Rohdendorf, B. B. 1930.64 h. Sarcophaginae. Die Fliegen der Paläarktischen Region, 11 (39), 1-48.

Rohdendorf, B. B. 1934. Egyptian Larvaevoridae collected by Prof. H. C. Efflatoun Bay (Diptera: Tachinidae). Bulletin de la Société Royale Entomologique de Égypte, 18, 1-16. 
Rohdendorf, B. B. 1970 Fam. Sarcophagidae - sarcophagids. In: Bey-Byenko, G. Ja., ed.. Key to Insects of the European Part of USSR, 5 (2). Nauka, Leningrad, 624-670 [In Russian].

Rohdendorf, B. B., Verves, Yu. G. 1980. On the fauna of Sarcophagidae (Diptera) of the Mongolian People's Republic. III. Miltogrammatinae. Insects of Mongolia, 7, 445-518.

Séguy, E. 1941. Études sur les mouches parasites. Tome 2. Calliphorines (suite), sarcophagines et rhinophorides de l'Europe occidentale et meridionale. Recherches sur la morphologie et la distribution géographique des Diptères à larves parasites. Encyclopèdie Entomologique, A 21, 1-436.

Szpila, K. 2010. The first instar of European Miltogramminae (Diptera: Sarcophaidae). PhD thesis, Nicolaus Copernicus University, Toruń, 1-272.

Szpila K., Pape, T. 2005. The first instar larva of Apodacra pulchra (Diptera: Sarcophagidae, Miltogramminae). Insect Systematics and Evolution, 36, 293-300.

Townsend, C. H. T. 1935. Manual of myiology in twelve parts. Part II. Muscoid classification and habits. Charles Townsend and Filhos, Itaquaquecetuba, São Paulo, 1-289 + pls 1-7.

Townsend, C. H. T. 1938. Manual of myiology in twelve parts. Part VI. Muscoid generic diagnoses and data. Stephanostomatini to Moriniini. Charles Townsend and Filhos, Itaquaquecetuba, São Paulo, 1-309.

Venturi, F. 1957. Notulae dipterologicae. XV. Esame critico delle Apodacra cyprica Rond. e bembicisequas Pand. e relative modoficazioni nomenclotariali. Bollettino della Società Entomologica Iitaliana, 87, 154-160.

Venturi, F. 1960. Sistematica e geonemia dei sarcofagidi (escl. Sarcophaga s. 1.) italiani (Diptera). Frustula Entomologica, 2 (7), 1-124.

Verves, Yu. G. 1984. On the fauna of Sarcophagidae (Diptera) of the Mongolian People's Republic. V. New data on sarcophagids from Mongolia and neighboring territories. Insects of Mongolia, 9, 527-561.

Verves, Yu. G. 1986. Family Sarcophagidae. In: Soós, Â. and Papp, L., eds. Catalogue of Palaearctic Diptera, 12, Akadémiai Kiadó, Budapest; Elsevier, Amsterdam, 58-193.

Verves, Yu. G. 1990. A key to Sarcophagidae (Diptera) of Mongolia, Siberia and neighbouring territories. Insects of Mongolia, 11, 516-616.

Verves, Y., Barták, M., Kubík, S. 2018. Checklist of flesh flies of Turkey (Diptera, Sarcophagidae). ZooKeys, 743, 95-136.

Verves, Y., Barták, M., Kubík, S., Civelek, H. S. 2017. New records of Sarcophagidae from Turkey (Diptera). ZooKeys 703, 129-158.

Verves, Yu., Khrokalo, L. 2006. Family Sarcophagidae. In: Sidorenko, V., ed. Key to Insects of Russian Far East, 6 (4). Vladivostok, Nauka, 64-178.

Verves, Yu. G., Khrokalo, L. A. 2014. An annotated list of the Sarcophagidae (Macronychiinae, Miltogramminae, Eumacronychiinae and Paramacronychiinae) recorded in Ukraine (Diptera). CESA News, 95, 1-47.

Verves, Yu. G., Khrokalo, L. A. 2018. The Sarcophagidae (Diptera) of the Middle East. Zoology in the Middle East, 64 (3), 273-282. Supplemental Material, 1-27.

Verves, Yu., Radchenko, V., Khrokalo, L. 2015. A review of species of subtribe Apodacrina Rohdendorf, 1967 with description of a new species of Apodacra Macquart, 1854 from Turkey (Insecta: Diptera: Sarcophagidae: Miltogramminae: Miltogrammini). Turkish Journal of Zoology, 39, 263-278.

Villeneuve, J. 1916. A contribution to the study of the South African higher myodarii (Diptera Calyptratae) based mostly on the material in the South African Museum. Annals of the South African Museum, 15, 469-515.

Villeneuve, J. 1933. Descriptions de Miltogamminae nouveaux (Dipt. Sarcophagidae). Bulletin de la Société Entomologique de France, 38, 254-257.

Zerova, M. D., Romasenko, L. P., Seryogina, L. Ya., Verves, Yu. G. 2006. Natural insect enemies of solitary bees of the fauna of Ukraine. Veles, Kyiv, 1-236 [In Ukrainian].

Zumpt, F. 1961. Calliphoridae (Diptera Cyclorrhapha). Part III: Miltogramminae. Exploration du Parc National Albert. Mission G. F. de Witte (1933-1935), 98, 1-137.

Received 16 June 2019

Accepted 25 February 2020 